\title{
ESTRUCTURAS DE PIEDRA E IMPACTO ANTRÓPICO RECIENTE EN ISLA LIEBRES (LOCALIDAD ARQUEOLÓGICA PUNTA MEDANOSA, COSTA NORTE DE SANTA CRUZ)
}

\author{
MIGUEL ÁNGEL ZUBIMENDI ${ }^{a}$
}

\begin{abstract}
RESUMEN
En este trabajo se presenta un estudio longitudinal a partir de la comparación de cuatro relevamientos realizados en la isla Liebres en la localidad arqueológica Punta Medanosa, costa norte de Santa Cruz (Patagonia argentina). La comparación entre los relevamientos realizados con más de 17 años de diferencia nos permite destacar que esta isla fue utilizada por parte de las poblaciones cazadoras recolectoras casi exclusivamente para la realización de entierros de tipo chenque durante el Holoceno tardío final. Éstos se distribuyen de forma no homogénea dentro de la isla, con una clara estructuración espacial en una pequeña playa, lo que permite plantear que se trataría de un lugar persistente para la inhumación por parte de las poblaciones del pasado. Por otro lado, en los últimos relevamientos se constató que la isla ha comenzado a ser utilizada con fines recreativos, dado que se identificaron nuevas estructuras -no registradas previamenteque conforman pircados y reparos de fogones. Estas nuevas estructuras se asocian a una importante contaminación, compuesta principalmente por basura (botellas de vidrio y plástico, latas, metales, bolsas, etc.), así como también a la alteración y modificación de algunos chenques, lo que redunda en un importante y creciente impacto sobre el registro arqueológico de esta isla.
\end{abstract}

PALABRAS CLAVE: estructuras de piedra, chenques, contaminación moderna, costa norte de Santa Cruz.

\section{STONE STRUCTURES AND RECENT ANTHROPIC IMPACT ON LIEBRES ISLAND (PUNTA MEDANOSA ARCHAEOLOGICAL LOCALITY, NORTH COAST OF SANTA CRUZ)}

\begin{abstract}
A longitudinal study is presented based on the comparison of four surveys carried out on isla Liebres, at the archaeological locality of Punta Medanosa in the north coast of Santa Cruz (Patagonia Argentina). The comparison between surveys separated by more than 17 years allows us to highlight that this island was used by hunter gatherers almost exclusively for chenque type burials during final late Holocene. These stone structures are heterogeneously distributed within the island, with a clear spatial

a CONICET. Unidad Académica Caleta Olivia, Universidad Nacional de la Patagonia Austral; División Arqueología.

Museo de La Plata. UNLP. Paseo del Bosque s/n. La Plata, Argentina. C. P. 1900. Argentina. $\$ mikelzubimendi@gmail.com
\end{abstract}


structuration on a small beach, which permits to consider that it was a persistent place for burial. On the other hand, in the last surveys new structures were identified -not previously registered- which indicates that the island has begun to be used for recreational purposes. Among these new structures there are stone fences and ovens, which are associated with significant contamination, mainly composed of garbage (glass and plastic bottles, cans, metals, bags, etc.), and the alteration and modification of some chenques, which results in an important and increasing impact on the archaeological record of this island.

KEY WORDS: stone structures, chenques, modern contamination, north coast of Santa Cruz.

\section{INTRODUCCIÓN}

En la costa norte de Santa Cruz (Patagonia argentina; de ahora en más CNSC) el registro arqueológico presenta una alta obstrusividad y se encuentra presente e integrado en la vida cotidiana de los actuales pobladores. En general, esta área se caracteriza por la presencia de extensos concheros, abrigos rocosos con evidencias arqueológicas y una alta densidad y concentración de estructuras de piedra de tipo chenque (e.g. Ambrústolo, 2011; Hammond, 2015; Zilio, 2015; Zubimendi \& Ambrústolo, 2016). Al tratarse de un área muy extensa, con muy escasa población rural, población urbana con poco arraigo territorial, y donde además existe una falta de interés y conocimiento de la protección del patrimonio cultural en buena parte de la población, así como escasas políticas públicas de protección del patrimonio natural y cultural, el registro arqueológico se encuentra sometido a una intensa presión, ya sea por el coleccionismo o el saqueo de los sitios arqueológicos (Zubimendi et al. 2015-2016).

En los últimos años los dueños de la estancia El Amanecer notificaron la existencia de alteraciones, por parte de visitantes ocasionales, sobre el registro arqueológico en la localidad arqueológica Punta Medanosa. En esta última existe un registro arqueológico sumamente interesante por su muy alta densidad y variabilidad de sitios (Castro et al. 2001a, 2001b; Moreno, 2009; Zilio et al. 2013; Hammond, 2015; Zilio, 2015; Zubimendi, 2019a), y por ser un destino conocido por los pobladores de las ciudades cercanas para la recolección de restos arqueológicos. En particular detallaron que las alteraciones recientes eran especialmente notorias en la isla Liebres, donde -de acuerdo a investigaciones realizadas desde el año 1999- existe gran cantidad de estructuras de entierro de tipo chenque (Castro \& Moreno, 2000;
Castro et al. 2001b). A partir de esta información, se realizaron nuevos relevamientos del registro arqueológico y las alteraciones existentes en esta isla para comparar la situación actual con la registrada en un relevamiento realizado en el año 2001, considerado este último como una línea de base. En este trabajo se presentan los resultados de la comparación e integración de varios relevamientos entre los años 2016 y 2018 -así como de otras fuentes, como fotografías e imágenes satelitales-, destacándose los distintos tipos de estructuras de piedra que se han identificado y las alteraciones antrópicas recientes que se han registrado. A su vez, se discute el posible uso de la isla Liebres en el marco de las ocupaciones humanas prehistóricas por parte de las poblaciones cazadoras recolectoras que vivieron en la CNSC durante el Holoceno tardío.

\section{La isla Liebres}

La isla Liebres se ubica en el extremo este de Punta Medanosa, al sur de la bahía de los Nodales, a aproximadamente $40 \mathrm{~km}$ al sur en línea recta de Puerto Deseado (Fig. 1). Se trata de una península que queda desconectada del continente dos veces al día durante las mareas altas. Si bien se encuentra a $150 \mathrm{~m}$ de la costa del continente, es fácil acceder a la misma a pie o con vehículos $4 \times 4$ por un puente de rodados de poco más de $200 \mathrm{~m}$ que se forma al bajar la marea. La isla presenta unas dimensiones aproximadas de 1.000 metros de largo por 290 metros de ancho máximo, y tiene una forma rectangular alargada en sentido noroeste-sudeste. Se trata de una isla rocosa que presenta extensas plataformas de abrasión de rocas ignimbríticas en sus costas y una cubierta sedimentaria de origen eólico (Giacosa et al. 1998). Es posible notar un nivel o terraza de aproximadamente $6 \mathrm{msnm}$ que 


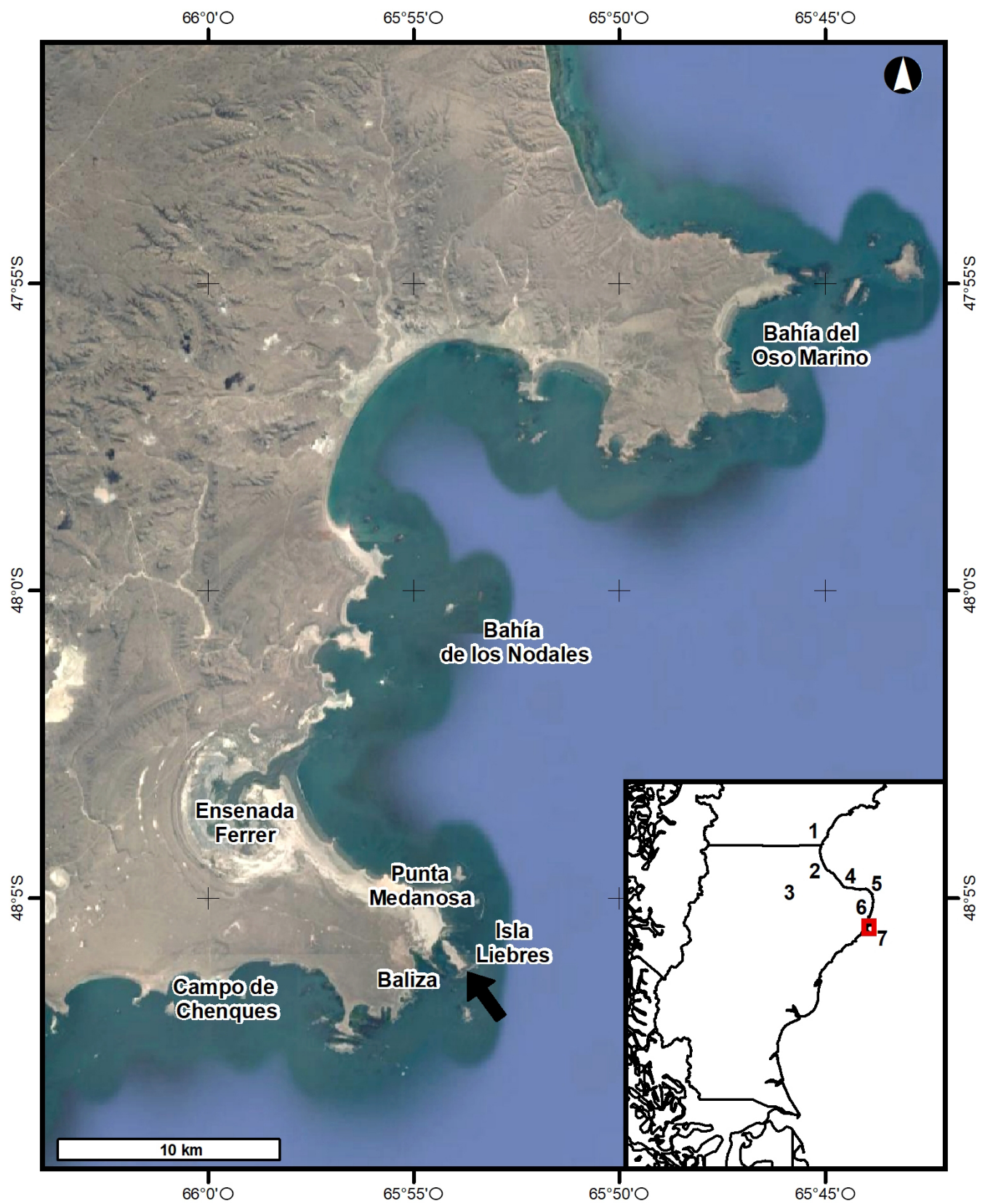

Fig. 1. Ubicación de la isla Liebres en la localidad arqueológica Punta Medanosa. Referencias: recuadro inferior derecho, ciudades y lugares mencionados: 1) Comodoro Rivadavia; 2) Caleta Olivia; 3) Pico Truncado;

4) Mazaredo; 5) Cabo Blanco; 6) Puerto Deseado; y 7) localidad arqueológica Punta Medanosa.

se extiende a lo largo de toda la parte central de la isla. En este momento no se observan arbustos, ya que la vegetación está compuesta por plantas herbáceas (Stipa, Poa y Festuca). Sin embargo, en el pasado se ha comprobado la presencia de escasos arbustos de molle (Schinus polygamus).
En cuanto a la fauna, en esta isla se ha descrito en el año 1994 la existencia de una colonia de nidificación de pingüinos de Magallanes (Spheniscus magellanicus) con unas 170 parejas reproductivas (Schiavini et al. 2005). También hay colonias de gaviota austral (Larus scoresbii) y gaviota 
cocinera (Larus dominicanus), contabilizándose en el año 1994, 17 y 210 parejas reproductivas respectivamente (Yorio, 2005). A su vez, de acuerdo al relevamiento realizado por Carrara (1952) a fines de la década de 1940 y comienzos de la década de 1950, en esta isla habría existido una colonia de lobos marinos de un pelo (Otaria flavescens), aunque la misma para la década de 1990 ya no pudo ser identificada (Grandi et al. 2015). Por su parte, durante los trabajos de campo se observó la presencia de ovejas (Ovis aries) y liebres europeas (Lepus europaeus) en la isla, así como bosta de caballo, por lo que estos últimos también deben ingresar con cierta regularidad.

En relación al registro arqueológico, esta isla fue visitada por primera vez en el verano del año 1999, momento en el que se identificó la presencia de 26 estructuras de piedra que fueron interpretadas como entierros de tipo chenque (Castro \& Moreno, 2000). Posteriormente, en el año 2001 se realizó un relevamiento específico de las estructuras de piedra de Punta Medanosa, en el cual se incluyó a la isla Liebres como un subsector particular, registrándose un total de 29 chenques (Castro \& Moreno, 2000; Castro et al. 2001b) y una estructura de piedra reciente ${ }^{1}$. Esta isla no volvió a ser analizada hasta el año 2016, a partir del cual se realizaron tres nuevos relevamientos, esta vez, focalizados en detectar y registrar alteraciones recientes.

\section{METODOLOGÍA}

En la isla Liebres se realizaron cuatro relevamientos exhaustivos en los veranos de los años 2001, 2016, 2017 y 2018. El objetivo general de los mismos fue relevar las características morfo-estructurales de las estructuras de piedra existentes que habían sido identificadas por primera vez en el año 1999 (Castro et al. 2001b). Estos relevamientos tuvieron algunas diferencias metodológicas producto de los cambios en las

1 También se registraron varios concheros, de media densidad superficial de valvas de moluscos y baja a muy baja de artefactos líticos, así como escasos restos óseos. Por sus características estructurales se diferencian de las grandes concentraciones de extensos concheros sobre médanos que existen en Punta Medanosa (Castro et al. 2001a; Hammond, 2015). Todos ellos se ubican en la parte central, más alta, de la isla. Las presencias de este tipo de formas de trabajo y los objetivos particulares con que fueron realizados. En el primer caso se pretendió relevar exclusivamente las estructuras de piedra, mientras que los tres últimos estuvieron orientados a la detección de alteraciones antrópicas recientes. En este trabajo integramos los resultados y realizamos un análisis comparativo longitudinal, lo que nos permite no solo dar cuenta del registro arqueológico de estructuras de piedra, sino también observar los cambios ocurridos desde comienzos de la década del 2000.

En el año 2001, y dada la gran cantidad de estructuras de piedra correspondientes a entierros de tipo chenque que se habían identificado en el año 1999 en la localidad arqueológica Punta Medanosa, se decidió realizar un relevamiento específico de este tipo de estructuras en toda la localidad. El objetivo del mismo fue conformar un mapa para analizar la ubicación y distribución de los entierros humanos en esta zona, así como establecer la densidad y los posibles patrones de distribución de las estructuras de piedra, para lo cual se relevaron, midieron y contabilizaron todas las estructuras de piedra, en especial aquellas que podían ser identificadas como probables chenques $^{2}$. Se empleó una ficha descriptiva en la que se consignó distinto tipo de información: a) Contextual, como fecha del relevamiento, número de estructura y posición geográfica; b) MorfoEstructural: ubicación geomorfológica, elementos constitutivos (materia prima, tamaño de la misma y procedencia), estado de alteración probable (cerrado o abierto) y otros rasgos descriptivos (presencia de vegetación, evidencias de alteraciones, etc.); c) Medidas, considerando el largo y ancho máximo de la distribución de elementos que conforman la estructura, así como el largo y ancho mínimo en aquellos casos que corresponden a estructuras en anillo o anulares, considerando las medidas del anillo interior que se encuentra libre de bloques, profundidad y orientación; d) Asociaciones, tanto a otras estructuras de piedra como a sitios concheros,

sitios permiten plantear que esta isla no solo fue utilizada como lugar de entierro, sino también con fines residenciales (Zubimendi, 2019a).

2 Esta actividad fue llevada a cabo en particular en la isla Liebres durante los días 25 y 30 de enero de 2001, y estuvo dirigida por C. Peña, junto con M. A. Andolfo, R. Giménez, E. Moreno y M. Á. Zubimendi. 

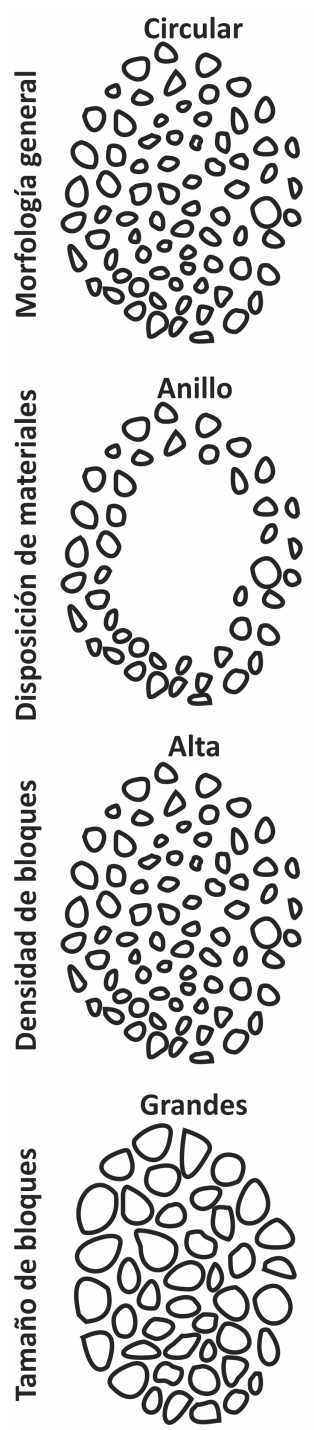
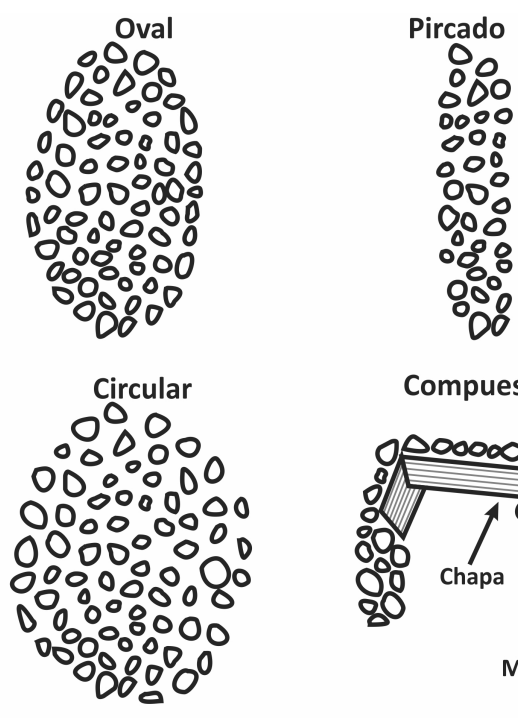

Compuesta
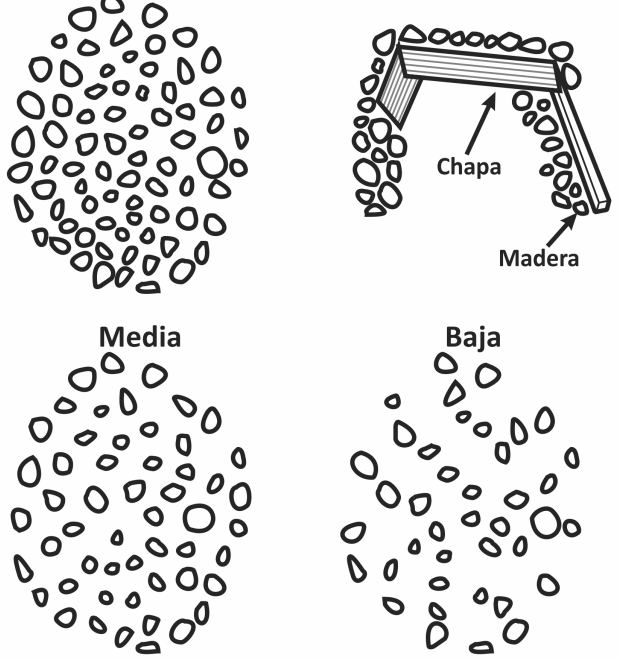

Chicos

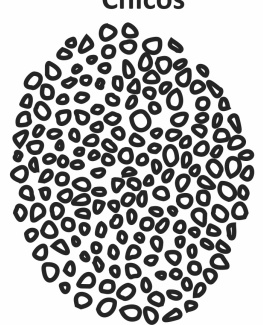

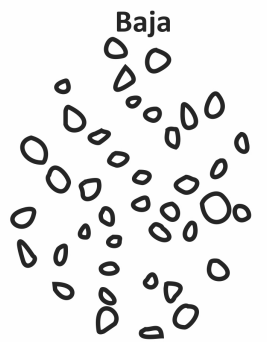

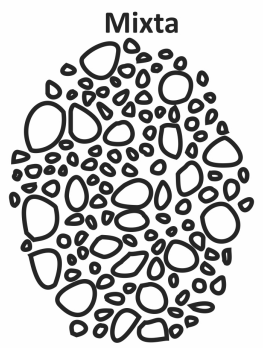

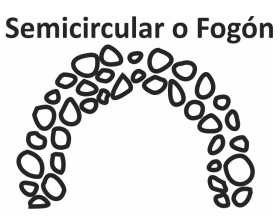

$$
\text { Indeterminada }
$$

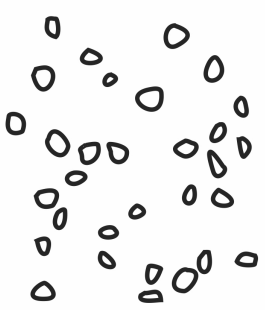

Fig. 2. Representaciones esquemáticas empleadas para la descripción morfológica de las estructuras de piedra identificadas en isla Liebres.

así como la presencia de otros materiales arqueológicos o modernos si los hubiera.

A partir del año 2016 se realizaron nuevos relevamientos motivados por la información brindada por los dueños de la estancia donde se ubica isla Liebres, según la cual ésta había comenzado a ser utilizada como un lugar de esparcimiento desde la apertura de la ruta Provincial $\mathrm{N}^{\circ} 83$, lo que permitió acceder de forma irrestricta

3 El primero de ellos se realizó el 14 de febrero de 2016 y participaron M. Á. Zubimendi y J. Rumbo; el segundo, el día 8 de marzo de 2017, formaron parte M. Á. Zubimendi, a la misma. Estos relevamientos ${ }^{3}$ se orientaron principalmente a registrar el estado de situación de las estructuras que habían sido identificadas en los trabajos previos, las nuevas estructuras creadas en los últimos años y la distribución de materiales modernos que contaminan con basura a la isla. Cada estructura de piedra o concentración de hallazgos arqueológicos fue registrada en una ficha, anotándose su posición geográfica y algunas

P. Ambrústolo y C. Contreras; y en el tercero, el día 13 de febrero de 2018, M. Á. Zubimendi, M. S. Caracotche y R. Blanco. 
variables de interés en el marco de los estudios que se realizan en el área y en la CNSC. Se consignaron variables tales como: a) Contextuales, punto GPS y posición satelital; b) Emplazamiento, considerando la cobertura vegetal, altura aproximada sobre el nivel del mar, morfología general, disposición de los materiales, densidad y tamaño de los bloques (Fig. 2), y características de la matriz sedimentaria (eólico no consolidado, consolidado, rodados, etc.); c) Restos arqueológicos: presencia y densidad de valvas, carbones, restos óseos, etc.; d) Aspectos postdepositacionales: tanto naturales, donde se registra la presencia/ausencia de distintos agentes o procesos que alteran el registro arqueológico (cuevas de roedores, la deflación de los médanos, el paso de pingüinos, la acción hídrica, la presencia de guano y huesos tafonómicos); y e) Antrópicos, donde se constata la presencia/ausencia de ciertos restos o evidencias de contaminación o acción moderna (basura de distinto tipo, las huellas del paso de vehículos, fogones modernos, etc.).

\section{RESULTADOS}

Como resultado de los cuatro relevamientos realizados se ha registrado (Tabla 1 ) un total de 37 estructuras de piedra indígenas -presumiblemente chenques, algunos de ellos alterados recientemente-, que se denominaron usando números arábigos; así como 18 estructuras recientes de distinto tipo ${ }^{4}$, que se consignaron utilizando letras mayúsculas. En la Tabla 2 se presenta una descripción morfológica general; los materiales asociados, arqueológicos o contemporáneos; y las dimensiones de los distintos tipos de estructuras, mientras que la distribución espacial se presenta en la Fig. 3. De esta forma, comprobamos que el paisaje actual de la isla Liebres se presenta como un complejo entramado de distintos tipos de estructuras que se encuentran en relación en este espacio acotado.

En isla Liebres, las estructuras en su gran mayoría han sido clasificadas como chenques $(67,3 \% ; n=37)$, entre éstos se observan distintos tipos, principalmente en anillo de forma oval o circular -esto es, que presentan un anillo de bloques de piedra y un espacio central con baja densidad o sin rocas- y con depresión central.

4 Solo se analizan aquellas estructuras compuestas por bloques rocosos, dejándose de lado en este análisis otras
Tabla 1. Tipos de estructuras de piedra identificadas en isla Liebres.

\begin{tabular}{llc}
\hline Tipo & Morfología & Cantidad \\
\hline \multirow{4}{*}{ Arqueológicos } & Chenque (no alterado) & $30(54,5 \%)$ \\
& Chenques alterados & $6(10,9 \%)$ \\
& Chenques con basura & $1(1,8 \%)$ \\
& Total & $37(67,3 \%)$ \\
\hline \multirow{3}{*}{ Recientes } & Fogones & $6(10,9 \%)$ \\
& Pircados & $4(7,3 \%)$ \\
& Estructuras & $8(14,5 \%)$ \\
\hline Total & Total & $18(32,7 \%)$ \\
\hline
\end{tabular}

En el relevamiento del año 2001 se consideró a este tipo de estructuras indígenas como alterado por aficionados en momentos históricos -últimos 100 años- estimándose que la forma en anillo era el resultado de la remoción de los bloques rocosos desde el interior y su depositación en los bordes (Castro et al. 2001b). En menor medida se registraron estructuras de menores dimensiones que presentan bloques rocosos en toda su superficie, que siguiendo la clasificación realizada en el año 2001 pueden ser consideradas cerradas o no alteradas $(8,6 \% ; n=3)$. Además, en la comparación con los relevamientos realizados en los últimos años, se constató que seis estructuras de piedra indígenas habían sido alteradas o sufrido algún tipo de modificación. En un caso en particular, se ha comprobado que un chenque fue desmontado para construir un fogón, lo que constituye un claro caso de reciclado de este tipo de estructuras.

\section{Estructuras de piedra indígenas}

Las estructuras de piedra indígenas identificadas en isla Liebres han sido interpretadas como entierros de tipo chenque (Castro \& Moreno, 2000; Castro et al. 2001b). Estas son estructuras de piedra que comúnmente refieren a enterratorios humanos que se encuentran demarcados superficialmente por una cubierta de rocas, y cuyos entierros se ubican a pocos centímetros por debajo. En general, en la Patagonia se encuentran aisladas, ubicadas en posiciones elevadas del terreno (Beron

alteraciones recientes, como los pozos de basura o la basura dispersa registrada en la isla (Zubimendi, 2019b). 
Tabla 2. Descripción morfológica de las estructuras de piedra relevadas en isla Liebres según su orden en sentido norte-sur.

\begin{tabular}{|c|c|}
\hline Est. & Morfología \\
\hline A & $\begin{array}{l}\text { Estructura indeterminada, densidad baja de } \\
\text { bloques chicos }\end{array}$ \\
\hline B & Fogón, densidad media de bloques grandes \\
\hline $\mathrm{C}$ & Pircado, densidad media de bloques grandes \\
\hline $\mathrm{D}$ & $\begin{array}{l}\text { Estructura indeterminada, densidad baja de } \\
\text { bloques chicos }\end{array}$ \\
\hline $\mathrm{E}$ & $\begin{array}{l}\text { Fogón compuesto, densidad media de bloques } \\
\text { grandes }\end{array}$ \\
\hline
\end{tabular}

F Fogón, densidad alta de bloques chicos, con basura (2016); estructura indeterminada, densidad baja de bloques chicos (2017 y 2018)

G Estructura indeterminada, densidad baja de bloques chicos

$\mathrm{H} \quad$ Estructura indeterminada, densidad media de bloques mixtos

I Fogón, densidad alta de bloques grandes

1 Estructura de piedra indígena circular, densidad alta de bloques chicos

2 Estructura de piedra indígena oval, densidad alta de bloques grandes (2001), alterada como pircado denso con basura (2016)

3 Estructura de piedra indígena oval en anillo, densidad alta de bloques mixtos (2001), alterada como fogón con basura (2016)

$4 \quad$ Estructura de piedra indígena oval, densidad baja de bloques chicos, con basura

5 Estructura de piedra indígena circular en anillo, densidad media de bloques grandes

6 Estructura de piedra indígena circular en anillo, densidad media de bloques grandes

J Fogón, densidad alta de bloques grandes

K Pircado, densidad media de bloques grandes

7 Estructura de piedra indígena circular en anillo, densidad media de bloques grandes

8 Estructura de piedra indígena oval en anillo, densidad baja de bloques mixtos

9 Estructura de piedra indígena oval en anillo, densidad media de bloques grandes
Botellas de vidrio, carbón, latas de cerveza,

plásticos, clavos, telas y huesos quemados

Maderas, frascos de vidrio, latas de cerveza, plásticos, metales y huesos quemados

Carbón, maderas, cartón, clavos, plásticos, restos orgánicos, latas de conserva, telas y vidrios

Huesos, clavos, plásticos, latas de conserva $y$ vidrios

Maderas, chapas, restos de pecio, huesos de cetáceo, latas de cerveza, metales, plásticos, restos orgánicos, latas de conserva, huesos quemados y tanzas de pesca

Botellas de vidrio y plásticos Medidas (m)

$4,4 \times 4,3$

$1,9 \times 1,3$

$1,35 \times 0,4$

$3 \times 2,7$

$3,4 \times 3,4$

Carbón y plásticos

$1,5 \times 1,3$

Carbón, metales y plásticos

$1 \times 0,4$

Huesos, cartón y plásticos

$1,4 \times 1,3$

$4,6 \times 4,5$

Nido de pingüinos y molle (2001), hierro,

$3,75 \times 2,6$

carbón, maderas, huesos de pingüinos

Vértebra humana (año 2001), latas de cerveza, caño metálico, huesos de pingüinos, cetáceo, aparejo de pesca

$3 \times 2,5$ (2017)

Madera, huesos de gaviotas

$3,7 \times 3$

$1,9 \times 1,5$ clavos, plásticos, restos orgánicos, huesos quemados $y$ vidrios

Carbón, huesos quemados y vidrio

$1 \times 0,6$

Restos arqueomalacológicos, artefactos líticos y escasos restos óseos, nido de ave

$3,6 \times 3,35$

Restos arqueomalacológicos, artefactos líticos y escasos restos óseos (pinnípedos)

$3,7 \times 2,6$

Nidos de gaviotas, carcasas de gaviotas 


\begin{tabular}{|c|c|c|c|}
\hline Est. & Morfología & Materiales asociados & Medidas (m) \\
\hline 10 & $\begin{array}{l}\text { Estructura de piedra indígena oval en anillo, } \\
\text { densidad media de bloques grandes }\end{array}$ & $\begin{array}{l}\text { Huesos de oveja, acumulación de } \\
\text { Macrocystis pyrifera secas, valvas de Mytilus } \\
\text { edulis y Aulacomya atra }\end{array}$ & $4,45 \times 3,4$ \\
\hline 11 & $\begin{array}{l}\text { Estructura de piedra indígena circular en anillo, } \\
\text { densidad baja de bloques mixtos }\end{array}$ & - & $2,8 \times 2,5$ \\
\hline 12 & $\begin{array}{l}\text { Estructura de piedra indígena oval en anillo, } \\
\text { densidad media de bloques grandes }\end{array}$ & - & $4,35 \times 3,32$ \\
\hline 13 & $\begin{array}{l}\text { Estructura de piedra indígena circular en anillo, } \\
\text { densidad media de bloques grandes }\end{array}$ & - & $4,65 \times 4,3$ \\
\hline 14 & $\begin{array}{l}\text { Estructura de piedra indígena (probablemente } 3 \text { ) } \\
\text { oval en anillo, densidad baja de bloques grandes }\end{array}$ & Huesos de gaviotas & $5,8 \times 4,8$ \\
\hline 15 & $\begin{array}{l}\text { Estructura de piedra indígena circular en anillo, } \\
\text { densidad baja de bloques grandes }\end{array}$ & - & $3,35 \times 3,15$ \\
\hline 16 & $\begin{array}{l}\text { Estructura de piedra indígena circular en anillo, } \\
\text { densidad baja de bloques grandes }\end{array}$ & - & $3,75 \times 3,6$ \\
\hline 17 & $\begin{array}{l}\text { Estructura de piedra indígena circular en anillo, } \\
\text { densidad baja de bloques grandes }\end{array}$ & $\begin{array}{l}\text { Huesos de mamíferos aserrados, nido de } \\
\text { gaviotas }\end{array}$ & $4,6 \times 4,4$ \\
\hline 18 & $\begin{array}{l}\text { Estructura de piedra indígena oval en anillo, } \\
\text { densidad media de bloques grandes }\end{array}$ & Nido de gaviotas & $4,65 \times 3,6$ \\
\hline 19 & $\begin{array}{l}\text { Estructura de piedra indígena oval en anillo, } \\
\text { densidad media de bloques grandes }\end{array}$ & - & $4,15 \times 2,15$ \\
\hline 20 & $\begin{array}{l}\text { Estructura de piedra indígena oval en anillo, } \\
\text { densidad baja de bloques grandes }\end{array}$ & Huesos de gaviotas & $3,5 \times 3,05$ \\
\hline 21 & $\begin{array}{l}\text { Estructura de piedra indígena oval en anillo, } \\
\text { densidad baja de bloques grandes }\end{array}$ & $\begin{array}{l}\text { Huesos de mamíferos aserrados, nido de } \\
\text { gaviotas }\end{array}$ & $4,35 \times 3,3$ \\
\hline 22 & $\begin{array}{l}\text { Estructura de piedra indígena circular en anillo, } \\
\text { densidad alta de bloques mixtos, con pozo } \\
\text { reciente y sedimento removido }\end{array}$ & Carcasas de gaviotas & $4,65 \times 4,3$ \\
\hline 23 & $\begin{array}{l}\text { Estructura de piedra indígena oval en anillo, } \\
\text { densidad media de bloques grandes }\end{array}$ & Nido de gaviotas & $4,35 \times 3,3$ \\
\hline 24 & $\begin{array}{l}\text { Estructura de piedra indígena oval en anillo, } \\
\text { densidad media de bloques grandes }\end{array}$ & Carcasas de gaviotas & $4,4 \times 3,6$ \\
\hline 25 & $\begin{array}{l}\text { Estructura de piedra indígena circular en anillo, } \\
\text { densidad media de bloques mixtos, alterada con } \\
\text { un pozo }\end{array}$ & - & $3,35 \times 3,3$ \\
\hline 26 & $\begin{array}{l}\text { Estructura de piedra indígena circular en anillo, } \\
\text { densidad media de bloques grandes, alterada con } \\
\text { un pozo rellenado }\end{array}$ & - & $4,1 \times 4$ \\
\hline 27 & $\begin{array}{l}\text { Estructura de piedra indígena circular en anillo, } \\
\text { densidad alta de bloques grandes }\end{array}$ & - & $5,3 \times 5,3$ \\
\hline 28 & $\begin{array}{l}\text { Estructura de piedra indígena circular en anillo, } \\
\text { densidad baja de bloques mixtos }\end{array}$ & Restos arqueomalacológicos, artefactos líticos & $3,5 \times 3,3$ \\
\hline 29 & $\begin{array}{l}\text { Estructura de piedra indígena oval en anillo, } \\
\text { densidad media de bloques grandes }\end{array}$ & $\begin{array}{l}\text { Restos arqueomalacológicos, huesos de } \\
\text { pinnípedos, tocones de arbustos }\end{array}$ & $4,05 \times 2,8$ \\
\hline $\mathrm{L}$ & $\begin{array}{l}\text { Estructura indeterminada, densidad alta de } \\
\text { bloques grandes }\end{array}$ & Botellas de vidrio & $2,4 \times 2,1$ \\
\hline M & $\begin{array}{l}\text { Estructura indeterminada, densidad media de } \\
\text { bloques grandes }\end{array}$ & Botellas de vidrio, huesos y vidrios & $2,4 \times 2$ \\
\hline
\end{tabular}




\begin{tabular}{|c|c|c|c|}
\hline Est. & Morfología & Materiales asociados & Medidas (m) \\
\hline $\mathrm{N}$ & $\begin{array}{l}\text { Fogón compuesto, con densidad alta de bloques } \\
\text { grandes }\end{array}$ & $\begin{array}{l}\text { Maderas, metales, cartón, plásticos, restos } \\
\text { orgánicos y telas }\end{array}$ & $2,2 \times 2$ \\
\hline $\mathrm{O}$ & $\begin{array}{l}\text { Estructura indeterminada, densidad media de } \\
\text { bloques grandes }\end{array}$ & Botellas de vidrio & - \\
\hline 30 & $\begin{array}{l}\text { Estructura de piedra indígena oval, densidad alta } \\
\text { de bloques mixtos, alterada con un pozo }\end{array}$ & Artefactos líticos, nido de gaviotas & $1,95 \times 1,2$ \\
\hline 31 & $\begin{array}{l}\text { Estructura de piedra indígena oval, densidad alta } \\
\text { de bloques mixtos }\end{array}$ & Huesos de ovejas & $3,4 \times 2,9$ \\
\hline 32 & $\begin{array}{l}\text { Estructura de piedra indígena oval, densidad alta } \\
\text { de bloques grandes }\end{array}$ & - & $2,65 \times 2,35$ \\
\hline 33 & $\begin{array}{l}\text { Estructura de piedra indígena circular en anillo, } \\
\text { densidad baja de bloques grandes }\end{array}$ & Carcasas de gaviotas & $4,2 \times 4,2$ \\
\hline 34 & $\begin{array}{l}\text { Estructura de piedra indígena circular en anillo, } \\
\text { densidad baja de bloques grandes }\end{array}$ & - & - \\
\hline 35 & $\begin{array}{l}\text { Estructura de piedra indígena circular en anillo, } \\
\text { densidad baja de bloques grandes }\end{array}$ & - & $3,35 \times 3,3$ \\
\hline 36 & $\begin{array}{l}\text { Estructura de piedra indígena oval en anillo, } \\
\text { densidad baja de bloques grandes }\end{array}$ & Nidos de gaviotas & $3,5 \times 3,2$ \\
\hline 37 & $\begin{array}{l}\text { Estructura de piedra indígena circular, densidad } \\
\text { baja de bloques grandes }\end{array}$ & Huesos de cetáceos & $3 \times 2,7$ \\
\hline $\mathrm{P}$ & Pircado, densidad media de bloques grandes & - & $2 \times 0,5$ \\
\hline Q & Pircado, densidad media de bloques grandes & Tanza de pesca & $20 \times 0,5$ \\
\hline $\mathrm{R}$ & $\begin{array}{l}\text { Fogón compuesto, con densidad alta de bloques } \\
\text { grandes }\end{array}$ & $\begin{array}{l}\text { Chapas, botellas de vidrio, metales, cartones, } \\
\text { clavos, plásticos }\end{array}$ & $1,5 \times 1,5$ \\
\hline
\end{tabular}

et al. 2000; Goñi \& Barrientos, 2000; Reyes, 2002; Reyes \& Méndez, 2010; Magnin, 2013). Este tipo de práctica de entierro presenta una significativa regularidad y homogeneidad en toda la Patagonia, ya que se lo registra desde el norte hasta el extremo sur de esta región. En cuanto a la antigüedad cronológica, es posible acotar su desarrollo a un período que abarca desde hace 1.500 años AP hasta momentos históricos (Reyes \& Méndez, 2010; Zilio, 2013). En el caso particular de la CNSC, los chenques han sido datados en un rango cronológico que abarca desde los 1.000 años AP hasta 300 años AP (Zilio, 2015; Zubimendi et al. 2015a). En este sentido, conviene aclarar que no se cuenta con fechados radiocarbónicos provenientes específicamente de isla Liebres, por lo que la asociación cronológica se realiza en base a la similitud morfológica y contextual.

Casi todos se asientan sobre sedimentos eólicos fijados por la vegetación o apoyados sobre conchilla. Aquellos ubicados sobre la parte central y más alta de la isla se asientan sobre sedimentos eólicos consolidados por vegetación herbácea y gravas, así como escasos rodados. En general presentan una muy baja cobertura vegetal (menor al 25\%), compuesta principalmente por plantas herbáceas. Los chenques han sido construidos con bloques rocosos de ignimbritas de tamaños variables que van de chicos a grandes. Los bloques se encuentran disponibles en las playas cercanas y han sido transportados hasta una distancia aproximada de $100 \mathrm{~m}$-algunos de ellos de varios $\mathrm{kg}$ de peso y volumen considerable- en el caso de aquellos chenques ubicados en la parte central de la isla. En este sentido, los chenques se ubican muy cerca de la costa, ya que el 78,3\% ( $\mathrm{n}=29)$ se encuentra a menos de $50 \mathrm{~m}$ de la playa más cercana; aunque se destacan algunos que se encuentran hasta a casi $100 \mathrm{~m}$ de la costa actual (Fig. 4). Además, 51,3\% $(n=19)$ está agrupado en torno a la playa noroeste de la isla a lo ancho de un tramo de solo $100 \mathrm{~m}$ de largo por 30 m de ancho (Fig. 3), con el lado mayor paralelo a la costa. Los chenques de isla Liebres en su mayoría se han definido como entierros abiertos 


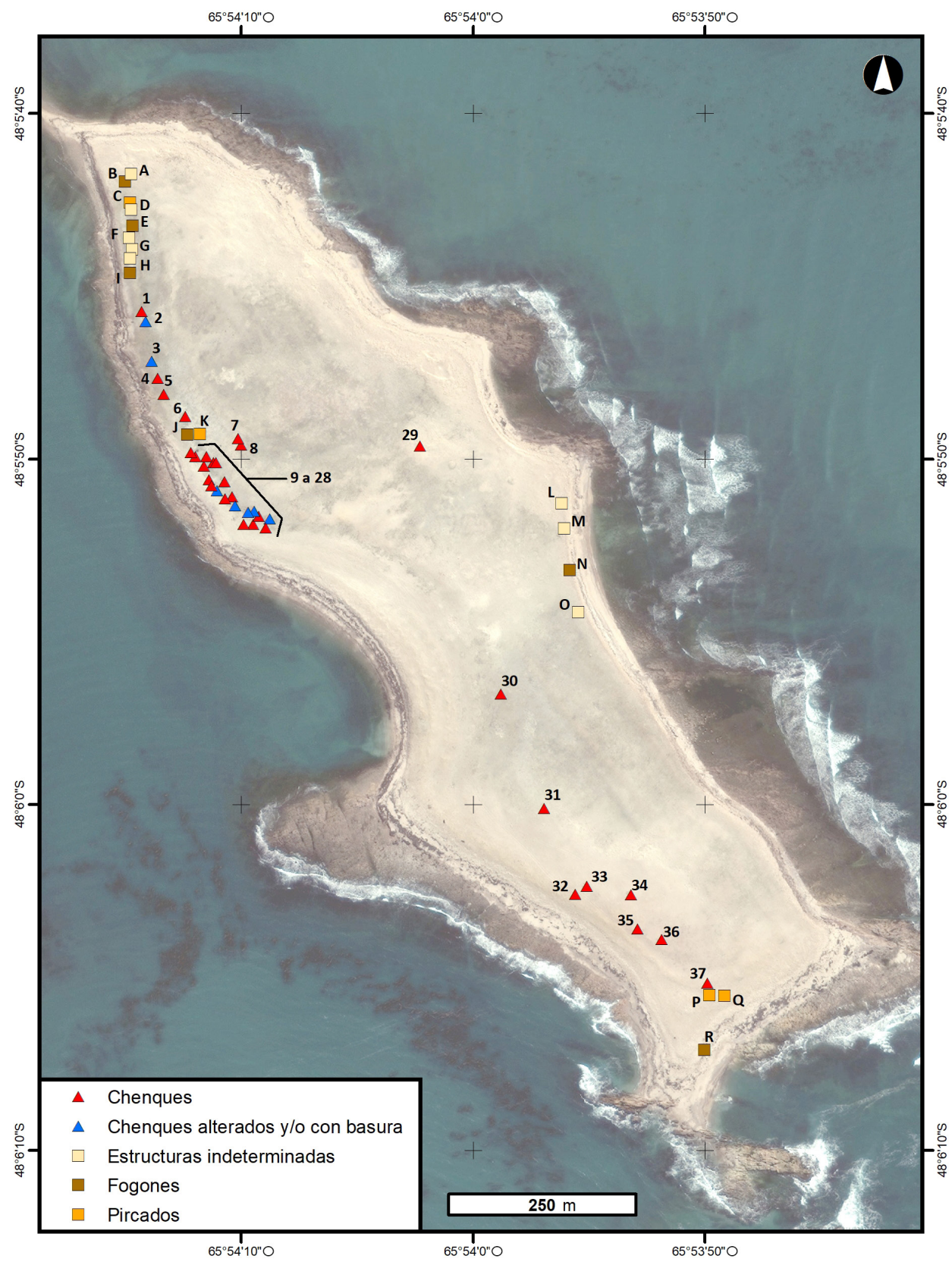

Fig. 3. Distribución espacial de los distintos tipos de estructuras de piedra identificadas en isla Liebres.

$(91,9 \% ; n=34)$, o sea, se presume que han sido alterados en algún momento del pasado (Castro \& Moreno, 2000). En la CNSC las estructuras clasificadas como chenques abiertos son muy comunes. Estas alteraciones o remociones habrian ocurrido hace tiempo, sin poder precisarse cuándo (Castro et al. 2001c; Goñi et al. 2005; Zilio, 2013, 2015; Zilio et al. 2013; Zilio \& Zubimendi,
2014). Sin duda, producto de estas alteraciones, la morfología y las dimensiones al momento de los relevamientos no estarían reflejando la forma original de los chenques. En general, aquellos considerados abiertos presentan hoy en día una morfología oval y en menor medida circular, con dimensiones variables que van desde los 3 a $6 \mathrm{~m}$ de largo máximo y 2,5 y $5 \mathrm{~m}$ de ancho máximo 
(Fig. 5), con un largo promedio de 4,02 $\pm 0,68$ $\mathrm{m} y$ un ancho de 3,46 $\pm 0,71 \mathrm{~m}$. Estos valores se encuentran dentro del rango de variabilidad de los chenques considerados abiertos de la CNSC (Zilio et al. 2013; Zilio \& Zubimendi, 2014; Zilio, 2015). Por su parte, el anillo o corona de bloques de piedra tiene un ancho variable $y$ un espacio central con menor densidad de rocas o vacío, en donde existe una depresión central (Fig. 6.a). Las medidas de este anillo central varían entre 3,2 y 0,7 $\mathrm{m}$ de largo.

Los chenques también varían en la densidad y dispersión de los bloques rocosos. Algunos presentan densas concentraciones de bloques, apoyados entre sí y superpuestos, mientras que otros se encuentran más dispersos y con menos cantidad de bloques (Fig. 6.b). En algunos casos, los bloques se encuentran parcialmente insertos en la matriz sedimentaria, semienterrados, lo que parece reflejar que éstos no han sido movidos en mucho tiempo. Prácticamente la totalidad de los bloques de las estructuras ubicadas en el centro y norte de la isla presenta líquenes en algunas de sus superficies, en algunos casos esto permite estimar cuáles habrían sido removidos en algún momento y cuáles no. En aquellas estructuras que se encuentran en la parte sur de la isla, los bloques están en su mayoría cubiertos por guano de gaviotas, y no se ha observado la presencia de líquenes (Fig. 6.c).

Otras estructuras $(n=5)$, por su parte, parecieran estar cerradas (Fig. 6.d), no haber sido removidas y podrían encontrarse en contexto primario. Esta clasificación tentativa se realiza en base a características morfológicas al momento

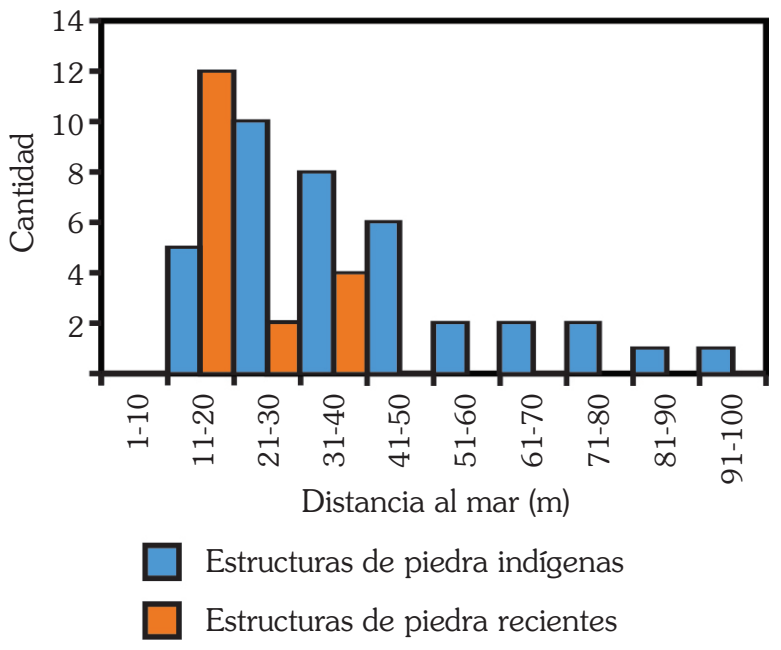

Fig. 4. Distancia al mar de las estructuras de piedra de isla Liebres. En azul las estructuras de piedra indígenas, en rojo las estructuras de piedra recientes.

del relevamiento, como: dimensiones más chicas que las estructuras definidas como abiertas -en general menores a $2,5 \mathrm{~m}$ de largo máximo (Magnin, 2013)-; presencia continua de rocas en toda su superficie y, por lo tanto, ausencia del anillo; así como en algunos casos una cubierta completa de líquenes que permite plantear que los bloques no han sido removidos (Garibotti et al. 2011). Las dimensiones promedio de las estructuras definidas como chenques cerrados son: $2,75 \pm 0,62 \mathrm{~m}$ y $2,29 \pm 0,76$ $\mathrm{m}$ de largo y ancho máximo respectivamente, valores menores en todos los casos a los de las estructuras abiertas (Fig. 5). Es difícil contrastar si esta clasificación es correcta, la única forma

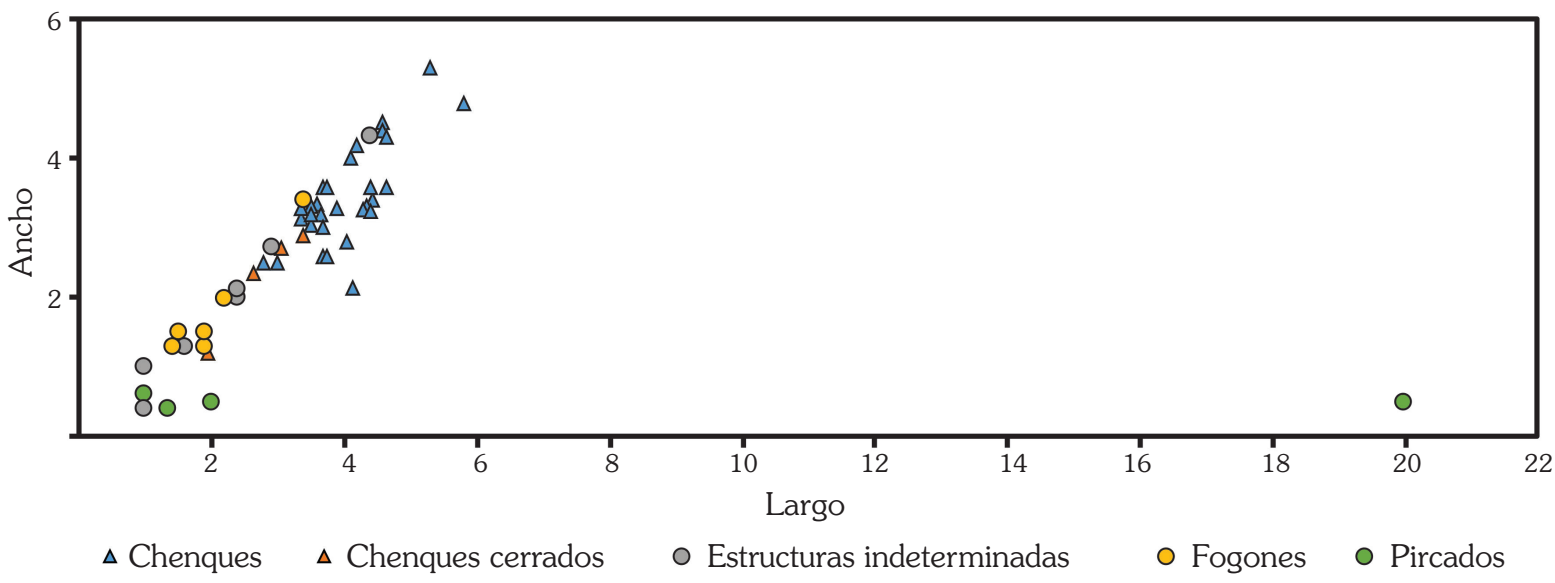

Fig. 5. Dimensiones de las estructuras de piedra de isla Liebres. 

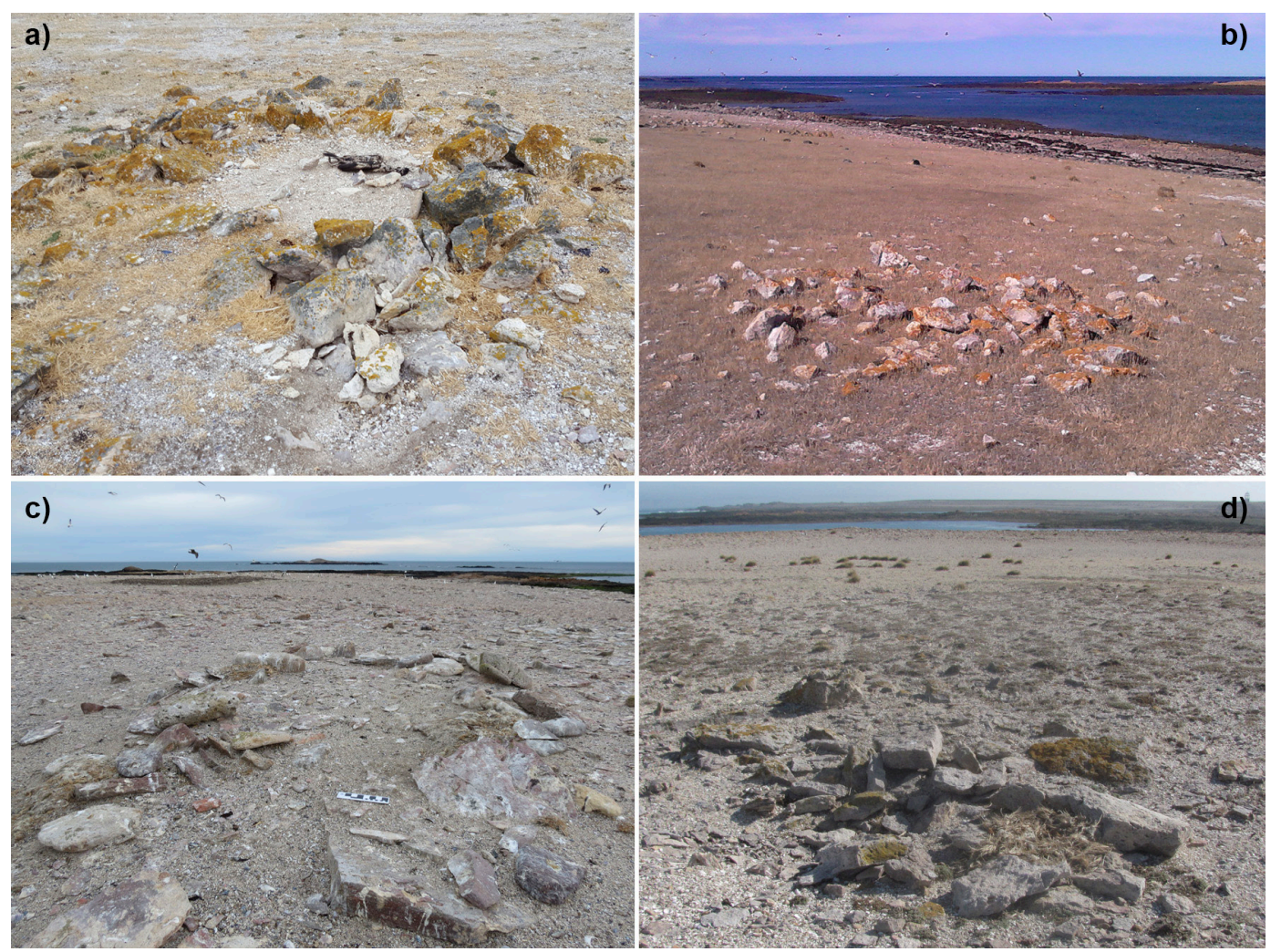

Fig. 6. Ejemplo de entierros de tipo chenque. Referencias: a) chenque circular en anillo de densidad alta de bloques rocosos, se observa en el centro una carcasa de gaviota, y en la parte inferior derecha un pozo reciente tapado con bloques (estructura 22); b) chenque circular de densidad media (estructura 6); c) chenque oval en anillo de densidad baja de bloques, se observa la superficie cubierta de bosteo de aves y la ausencia de líquenes, así como un nido de gaviota a la derecha (estructura 36); y d) chenque oval definido como probable cerrado, en el extremo derecho se halla un nido de gaviota (estructura 30).

de corroborar fehacientemente que se trate de estructuras de entierro de tipo chenque cerradas es excavarlas. Al respecto, sondeos exploratorios realizados en la localidad arqueológica Campo de Chenques confirmaron que estructuras definidas como abiertas presentaban restos óseos humanos alterados (Castro et al. 2001b; Goñi et al. 2005); mientras que otras estructuras de la CNSC que fueron definidas como cerradas y excavadas por encontrarse en inminente riesgo de destrucción resultaron ser entierros no alterados (Castro et al. 2000; Salceda et al. 1999-2001), lo que refuerza estas interpretaciones (Zilio, 2015). A su vez, en el relevamiento del año 2001 en isla Liebres, se registró en superficie una vértebra humana en una estructura, lo que refuerza la afirmación de que se trataría de entierros de tipo chenque.
En cuanto a las estructuras indígenas alteradas, se destacan algunos casos que analizaremos en detalle. El chenque 3 fue definido como abierto con morfología anular con depresión central en el año 2001. En los relevamientos de los años 2016 y 2017 se lo registró como pircado semicircular con una pared de ca. $40 \mathrm{~cm}$ de altura, mientras que en el 2018 presentaba además un pequeño pircado que cerraba parcialmente la estructura semicircular previa. Este es el único caso comprobado en que un entierro de tipo chenque fue modificado para un uso reciente (Fig. 7). A su vez, es de destacar que esta estructura es aquella en la que se registró una vértebra humana en el año 2001.

Otro caso particular lo constituye la estructura 2, la cual había sido visitada y relevada en los años 1999 y 2001. En aquellas oportunidades se destacaba por la presencia de un gran molle 
(Schinus sp.), inclinado en cuyo interior existía un nido de Spheniscus magellanicus con crías (Fig. 8.a), según se pudo constatar en los dos años en que se visitó la isla. Sin embargo, en el año 2016 se comprobó la ausencia del nido de pingüinos y del molle que crecía desde el centro del chenque, quedando solo el tocón del mismo (Fig. 8.b). Para confirmar que se trataba del mismo chenque se procedió a realizar comparaciones de imágenes satelitales de los años 2002 y 2011. Más allá de las diferencias en la calidad, se observa una mancha de color oscuro rodeado de un halo de color más claro en la imagen del 2002, mancha que no se registra en las imágenes del año 2011 (Fig. 9). Otras fuentes para analizar la ausencia de este molle son las fotografías. En la Fig. 10 se presenta una comparación de tres fotografías, en las cuales es posible observar el arbusto de molle en tres momentos: en la fotografía superior (Fig. 10.a) se ve el molle -probablemente entero como fue registrado en los años 1999 y 2001-; mientras que en las fotografías de los años 2011 y 2012 (Fig. 10.b y c) el molle ya está talado, aunque probablemente de forma parcial, sin follaje, porque se alcanza a visualizar algo que sobresale por sobre el terreno. De esta forma, es posible acotar el tiempo en el que fue talado de forma definitiva, ya que habría ocurrido entre los años 2012 y 2016. Es probable que este arbusto haya sido utilizado como leña, como la que se observa acumulada en varias estructuras recientes. Conviene mencionar que la cueva de pingüinos era la única existente en el noroeste de isla Liebres. Esto es de gran interés dado que en esta isla se habían contabilizado 170 parejas reproductivas en el año 1994 (Schiavini et al. 2005). Es probable que, si la isla es visitada por humanos con cierta regularidad durante los meses de verano en que los pingüinos anidan, éstos se alejen de la presencia humana o se hayan retirado completamente de la isla, lo que suma un factor más de alteración producida en los últimos años (Cevasco et al. 2001).
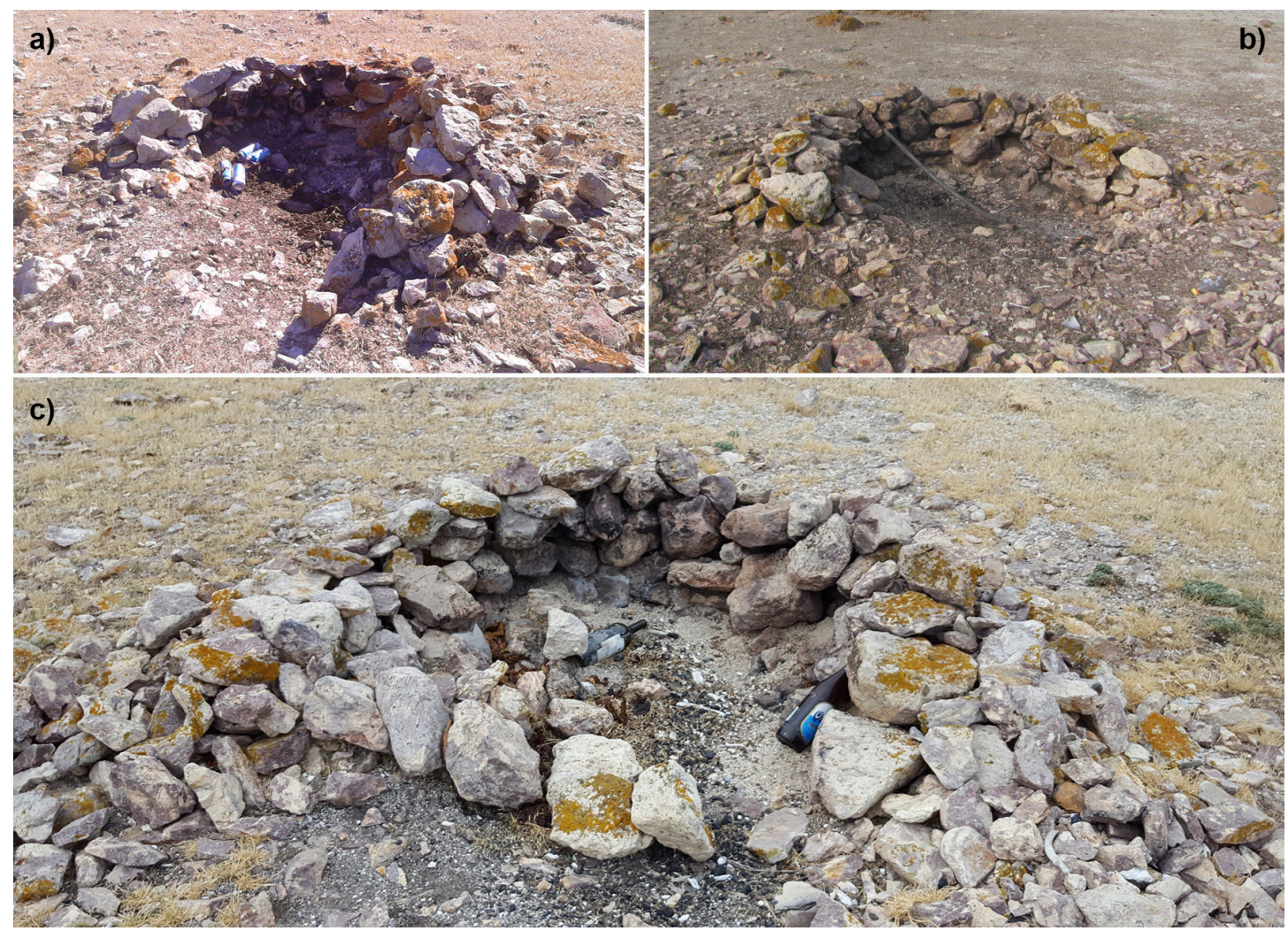

Fig. 7. Comparación de fotos de la estructura 3. Referencias:

a) fotografía del año 2016; b) año 2017, nótese el espacio central libre de basura; y c) año 2018 , con la nueva estructura cerrando parcialmente el espacio central. 


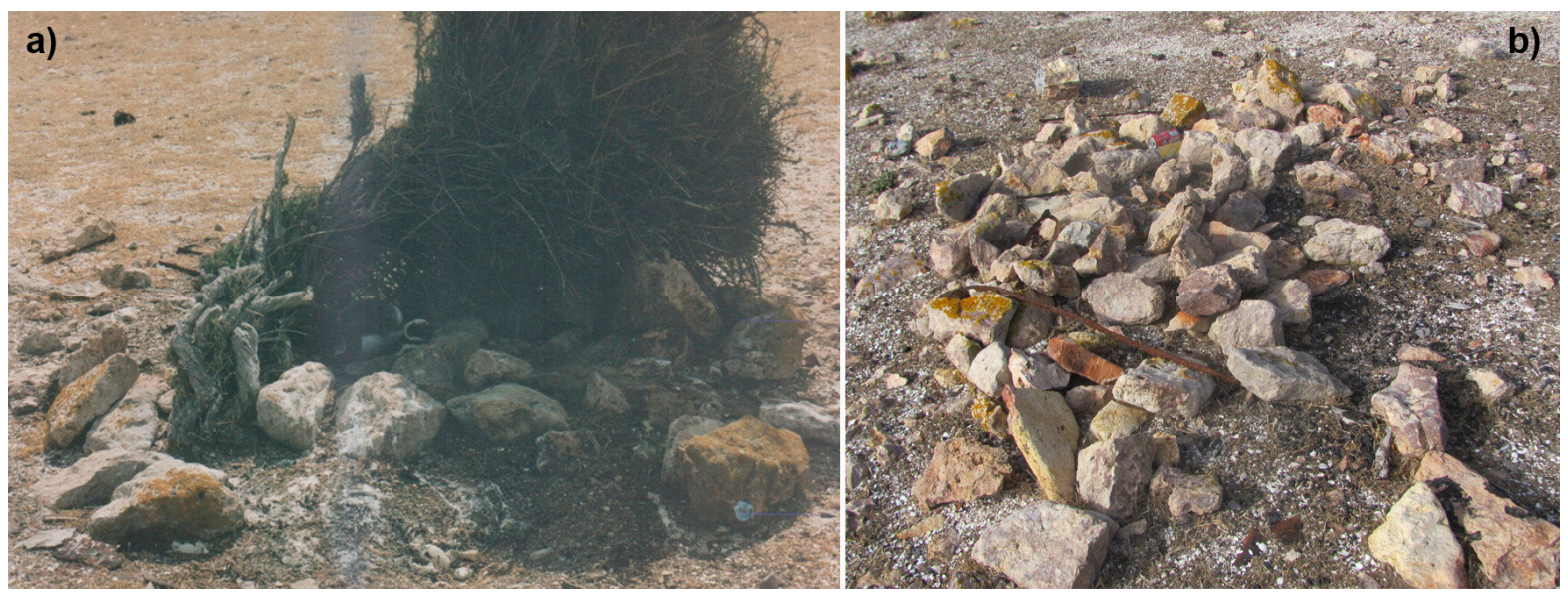

Fig. 8. Comparación de fotos de la estructura 2. Referencias: a) fotografía del año 1999, en el centro se observa un pingüino de Magallanes; y b) fotografía del año 2016.
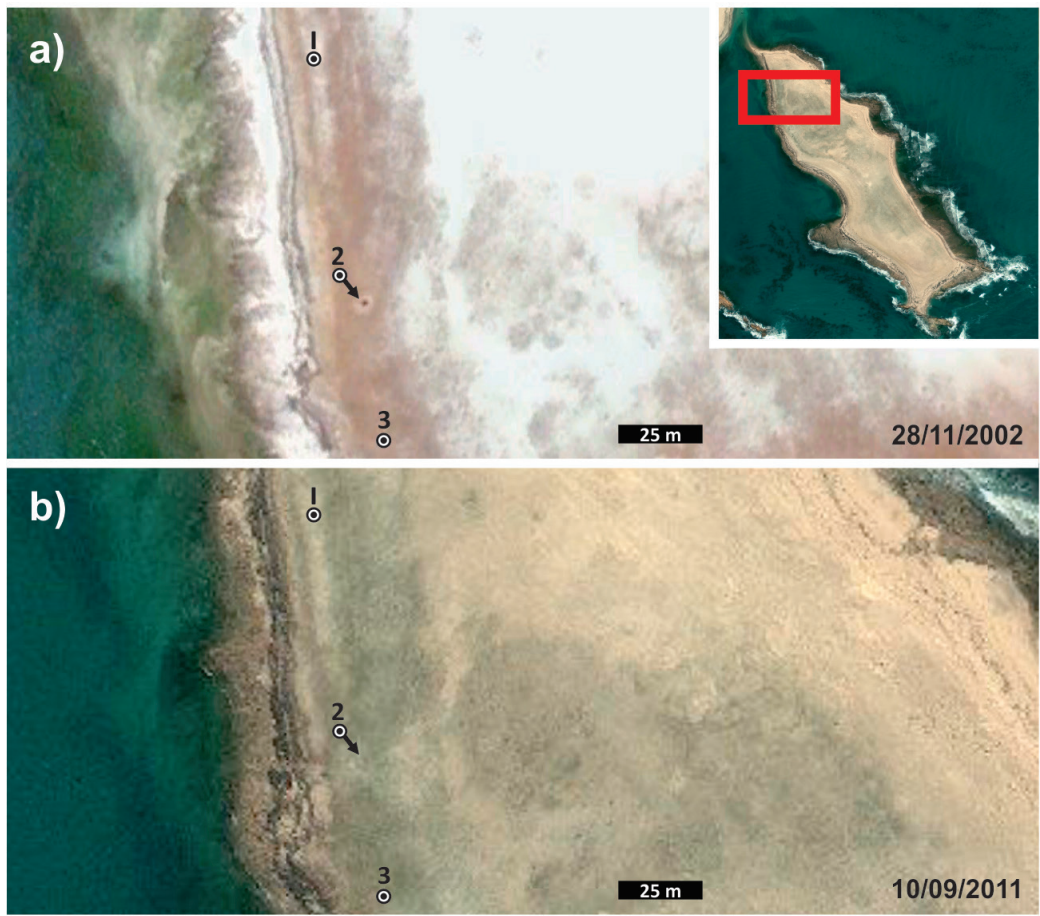

Fig. 9. Comparación de imágenes satelitales para observar la ausencia del molle de la estructura 2.

Referencias: a) se observa la mancha que constituye el chenque 2 en la imagen del 28/11/2002;

b) y c) la mancha se encuentra ausente en las fotografías del 10/9/2011 y $13 / 12 / 2011$.

Fuente: a) y c) Google Maps (https:// www.google.com.ar/maps); b) Bing Maps (www.bing.com/maps/).

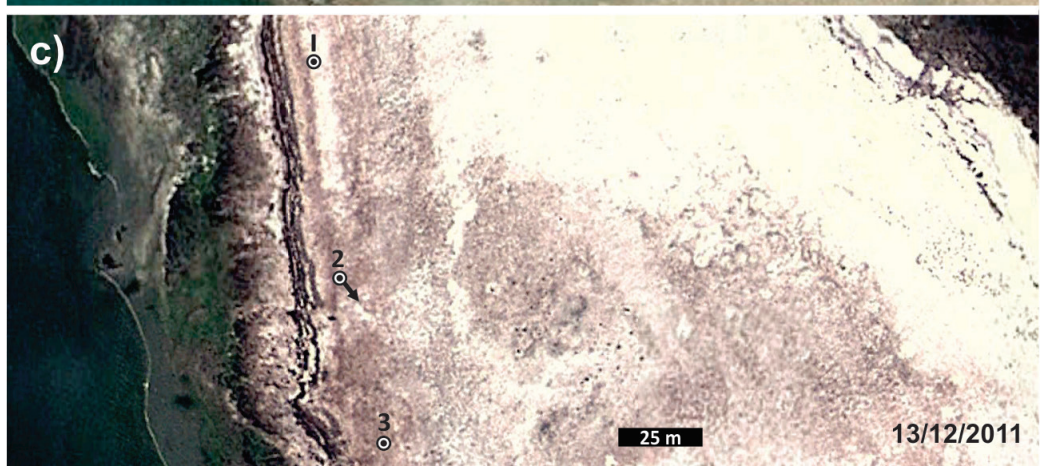



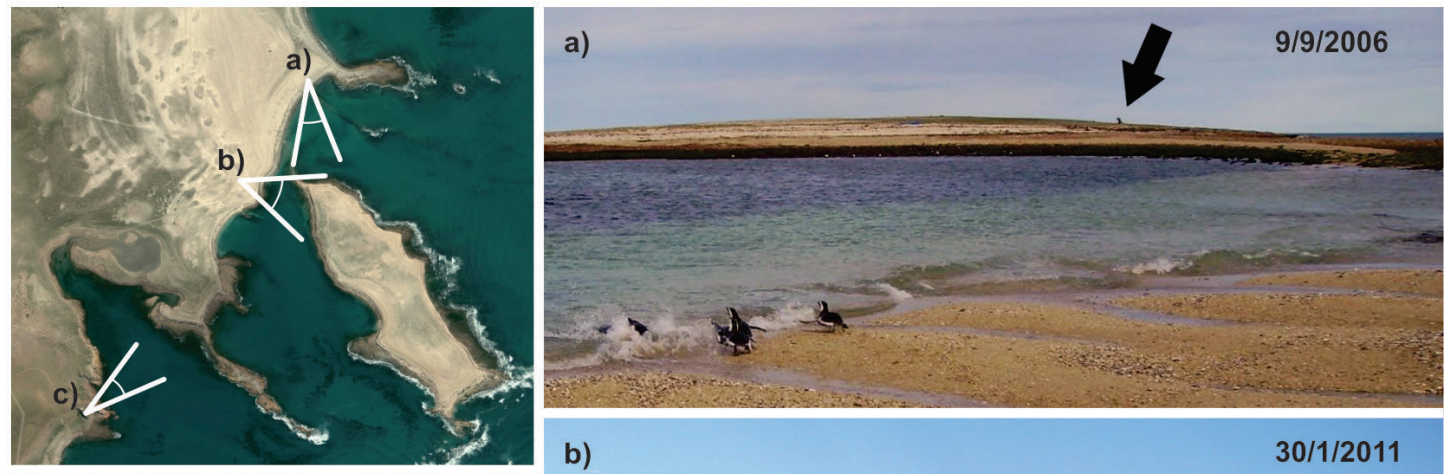

b)

$30 / 1 / 2011$

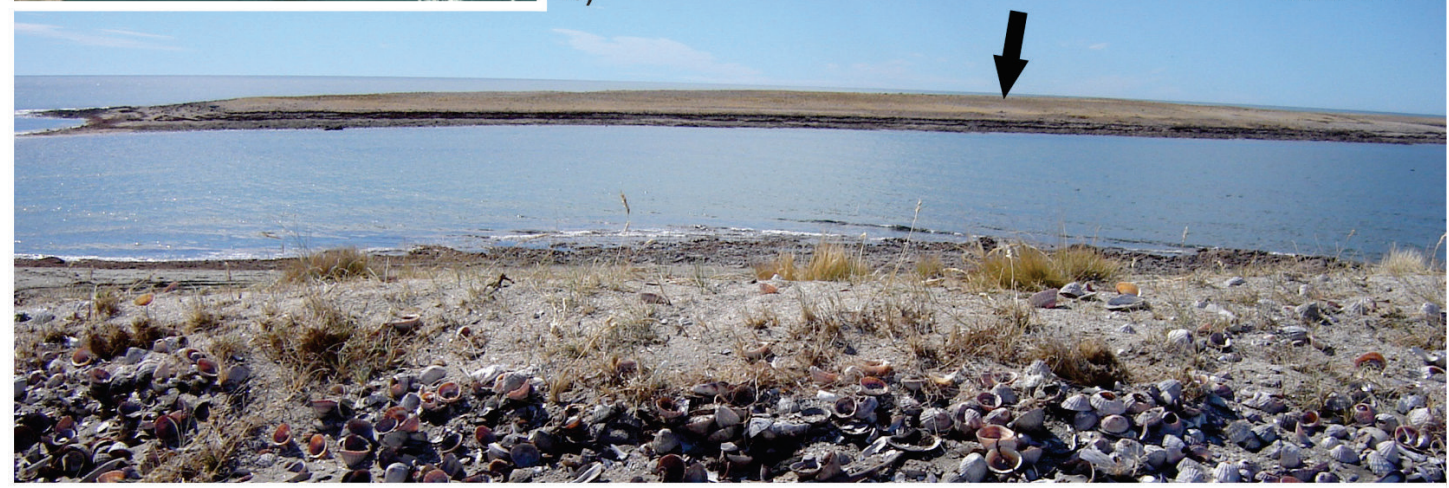

c)

$26 / 1 / 2012$

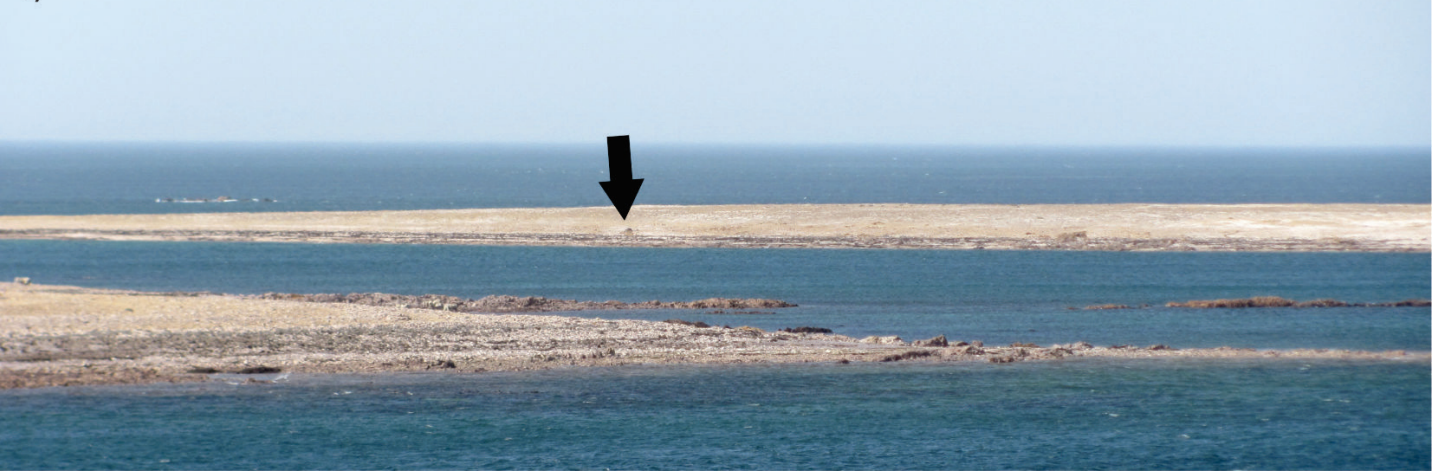

Fig. 10. Comparación fotográfica del molle en el chenque 2. Referencias: a) fotografía de M. Lobato desde la playa norte de Punta Medanosa, al noroeste de isla Liebres, donde se observa el arbusto de molle que sobresale por sobre el perfil de la isla (imagen modificada de http://www.panoramio.com/photo/14567336); b) fotografía de H. Hammond

desde la playa ubicada en Punta Medanosa, al este frente a isla Liebres, donde se observa el arbusto de molle parcialmente talado; y c) fotografía propia desde la baliza, ubicada al sur de isla Liebres, donde se observa el arbusto de molle parcialmente talado. En todas las fotografías la flecha negra señala la posición del molle.

Los restantes chenques alterados presentan algunos pequeños pozos en la depresión central o la remoción de bloques rocosos (Fig. 6.b). En estos casos, no es posible estimar el motivo de las alteraciones, ya que las mismas no alcanzan a conformar nuevas estructuras a partir del uso de bloques del chenque original, ni parecen ser el producto de pozos de saqueo. Sin embargo, las alteraciones se pueden constatar por cambios en los sedimentos y la ausencia de líquenes en algunas caras expuestas de bloques rocosos.

La mayoría de las estructuras de piedra indígenas $(n=18)$ presenta algún tipo de asociación espacial con otros restos arqueológicos, 
contaminación con restos naturales o basura reciente. Varias se ubican espacialmente asociados con otros restos arqueológicos $(n=5)$. Todos ellos se ubican sobre la terraza alta que tiene una altura de ca. $6 \mathrm{msnm}$. Estas estructuras se asocian a concentraciones de artefactos líticos de densidades bajas, de materias primas no disponibles en la isla (entre otras, obsidiana y sílices rojos); y muy baja de restos óseos, entre los que se pudieron identificar huesos de pinnípedos insertos en la matriz sedimentaria de conchero. En cuanto a los moluscos, se registran dispersiones de media a baja densidad de valvas, mayormente Nacella magellanica, y en menor medida Mytilus edulis y Aulacomya atra; aunque también se han observado ejemplares de Adelomelon sp. y Trophon sp. En general, estas son las especies que se registran mayormente en los concheros de la CNSC y la costa patagónica (Hammond, 2015; Zubimendi et al. 2015b). Es interesante la asociación de chenques y concheros en isla Liebres, ya que en pocos casos en la CNSC los entierros de tipo chenque están asociados a otros restos arqueológicos, ya que en general se encuentran segregados espacialmente (Zilio, 2015; Zubimendi, 2019a).

Por otro lado, algunas estructuras de piedra indígenas registraron también distintos tipos de restos naturales que podrían, eventualmente, contaminar el registro arqueológico. Entre éstos, los nidos (Fig. 6.c y d) o carcasas con distinto grado de desarticulación de gaviotas cocineras y australes (Fig. 6.a) son los más comunes En menor medida, se observaron también huesos de pingüinos $y$ de oveja, que pudieron haber muerto de forma natural en la isla, conformando la denominada lluvia tafonómica natural (Borrero, 1988) en isla Liebres. Mientras que cinco estructuras indígenas presentan contaminación antrópica moderna. De éstas, dos son los casos mencionados previamente, las estructuras alteradas 2 y 3 . En la primera, se observaron varillas metálicas, latas de cerveza, vidrios y corchos de botellas de bebidas alcohólicas, maderas, restos de carbón y aparejos de pesca (tanza, anzuelos, etc.). Por su parte, en la estructura 3 pudimos comprobar cambios en los sucesivos relevamientos (Fig. 7): en el año 2016 presentaba latas de cerveza en el espacio protegido y, cerca, un caño metálico; al año siguiente el espacio central contenía únicamente carbón y, en el último relevamiento, botellas de vidrio de bebidas alcohólicas. Mientras que al caño metálico se lo registró en distintas localizaciones en torno y dentro de la estructura en los tres momentos. Todo esto permite afirmar que el chenque modificado como fogón semicircular fue utilizado a lo largo de los años analizados en repetidas oportunidades, aunque presumiblemente para el mismo fin, proteger el fuego del viento para cocinar. En las restantes estructuras con basura, se registraron maderas y huesos de mamíferos aserrados con bordes rectos y marcas que denotan que fueron cortados con máquinas, por lo que se infiere que habrían sido transportados ya cortados y su presencia dentro de las estructuras constituye basura moderna, y no parte de la lluvia tafonómica natural en la isla.

\section{Estructuras de piedra recientes}

De acuerdo con referencias de los dueños de la estancia donde se ubica esta isla y observaciones propias, la gran mayoría de las estructuras de piedra recientes habría sido producida por visitantes ocasionales que acampan en la isla. En general son grupos de hombres $y$, en algunos casos, grupos familiares, que van a practicar la pesca artesanal. Esta actividad suele ser complementada con la caza ilegal y la recolección de restos arqueológicos. Según referencias, los visitantes suelen proceder de Puerto Deseado, la ciudad más cercana, aunque también de otras localidades, principalmente de la cuenca petrolera: Caleta Olivia, Comodoro Rivadavia y Pico Truncado (Fig. 1). Cuando permanecen en la isla, practican la pesca deportiva y el disfrute de las playas que, si bien se realiza a lo largo de todo el año, se desarrolla principalmente entre los meses de octubre a marzo. Así, isla Liebres, como otros lugares similares elegidos para la pesca en la CNSC (por ejemplo, Mazaredo y Cabo Blanco), forman parte de un circuito informal en el que se hace uso, sin control, de la costa y sus recursos, sin la mediación o salvaguarda por parte de entes o agencias de turismo locales o instituciones dedicadas a la conservación del medio ambiente (sensu Manzi \& Borella, 2009).

La primera estructura que podemos denominar reciente, esto es, que no corresponde a épocas indígenas, fue registrada en el año 
2001 en el extremo sur de la isla Liebres. En dicha oportunidad se describió una alineación de rocas asociada espacialmente a redes para la captura de algas de Macrocystis pyrifera, un alga de interés comercial que era explotada en ese entonces por los dueños de la estancia. Sin embargo, es a partir del relevamiento del 2016 en que se registra un creciente número y diversidad de estructuras de piedra, junto con otro tipo de evidencias -como basura suelta, pozos de basuraen la isla Liebres (ver Zubimendi, 2019b, para una caracterización de los mismos). En relación con las primeras, podemos diferenciar tres tipos: fogones semicirculares; pircados o alineaciones; $y$ estructuras indeterminadas.

Losfogonescorrespondenmorfológicamente a acumulaciones de bloques rocosos ignimbríticos dispuestos de forma semicircular, que conforman paredes en seco, sin argamasa. Todos ellos han sido construidos luego del relevamiento del año 2001, ya que en dicha oportunidad no fueron registrados ${ }^{5}$. Se asientan generalmente sobre sedimentos eólicos fijados por vegetación, con una cobertura vegetal cercana al 25\%, compuesta mayormente por especies herbáceas. En algunos casos se asientan sobre un nivel de conchilla; mientras que los ubicados más cerca del mar, se encuentran apoyados sobre un cordón de rocas ignimbríticas. Para realizar estas estructuras se han empleado bloques rocosos, disponibles en las cercanías, de tamaños medianos a grandes.

Constan de bloques rocosos apilados, en general conformando semicírculos que protegen un espacio interno (Fig. 11.a). El tamaño de estas estructuras varía entre 1,4 y 3,4 m de largo máximo, con un promedio de 2,05 \pm 0,72 m de largo y $1,83 \pm 0,81 \mathrm{~m}$ de ancho, constatándose una baja variabilidad en el tamaño (Fig. 5). En algunos casos se infiere que la construcción de los fogones ha implicado una inversión de energía significativa, ya que se emplearon bloques de gran tamaño y varios kilos de peso. La morfología de

5 Por referencias de los dueños de la estancia, las estructuras de este tipo han sido erigidas con posterioridad al año 2013, momento en que la municipalidad de Puerto Deseado produjo la apertura de la ruta Provincial $N^{\circ} 83$ que permite el acceso irrestricto a la localidad arqueológica Punta Medanosa. Hasta ese momento, se requería la autorización de los dueños del campo, por lo que la entrada a la costa estaba limitada y controlada. los fogones y la presencia de carbones vegetales y huesos quemados, junto con basura y asadores, permiten inferir que han sido usados para realizar asados.

Estos fogones se registraron con distintos grados de conservación, ya que algunos se encontraban en buen estado, conformando acumulaciones de bloques rocosos con una altura de aproximadamente entre 40 y $50 \mathrm{~cm}$ (Fig. 11.b), mientras que otros se encontraban desmoronados (Fig. 11.c). En algunos casos se construyeron fogones mixtos, empleando tanto rocas locales como chapas acanaladas, maderas o incluso cuadernas de pecios cercanos o grandes huesos de cetáceos (Fig. 11.d). A su vez, en los distintos relevamientos se observaron casos de fogones que fueron desarmados y la construcción de nuevos, tanto cerca de anteriores como en otras zonas de la isla. En el caso particular de la estructura E, ésta aumentó en tamaño, complejidad y cantidad de elementos empleados en su construcción: en el año 2016 constaba de dos chapas de más de 1 $\mathrm{m}$ de largo, sostenidas con piedras para generar un espacio protegido (Fig. 12.a); al año siguiente, la estructura estaba compuesta por gran cantidad de chapas metálicas, encerrando un espacio más grande, y una cuaderna metálica -resto de un naufragio cercano ${ }^{6}$ - formaba parte de la estructura de sostén (Fig. 12.b); por último, en el año 2018 era de mayores dimensiones y existían dos espacios separados por una gran chapa metálica, y además se sumó otra cuaderna a la estructura (Fig. 12.c). Por otro lado, ya desde el año 2017, la estructura era claramente visible desde algunas partes de Punta Medanosa, dado que sobresalía en altura sobre el perfil de isla Liebres (Fig. 12.d), por lo que constituía un atractor visual para que otras personas lo utilicen durante sus visitas.

Los fogones semicirculares se registraron inicialmente en la parte noroeste de la isla Liebres, aunque en los sucesivos relevamientos se constató que se construyeron nuevas estructuras recientes

6 Estas se encuentran cubiertas de crustáceos cirrípedos. Existen dos pecios en las cercanías, al norte de isla Liebres uno que es accesible a pie por estar en el horizonte inferior del intermareal y otro en el nivel submareal al sur de la isla. A su vez, se observa gran cantidad de restos de naufragio en la línea de resaca de temporales, entre ellos cuadernas (obs. pers. realizadas junto a S. Caracotche y R. Blanco). 

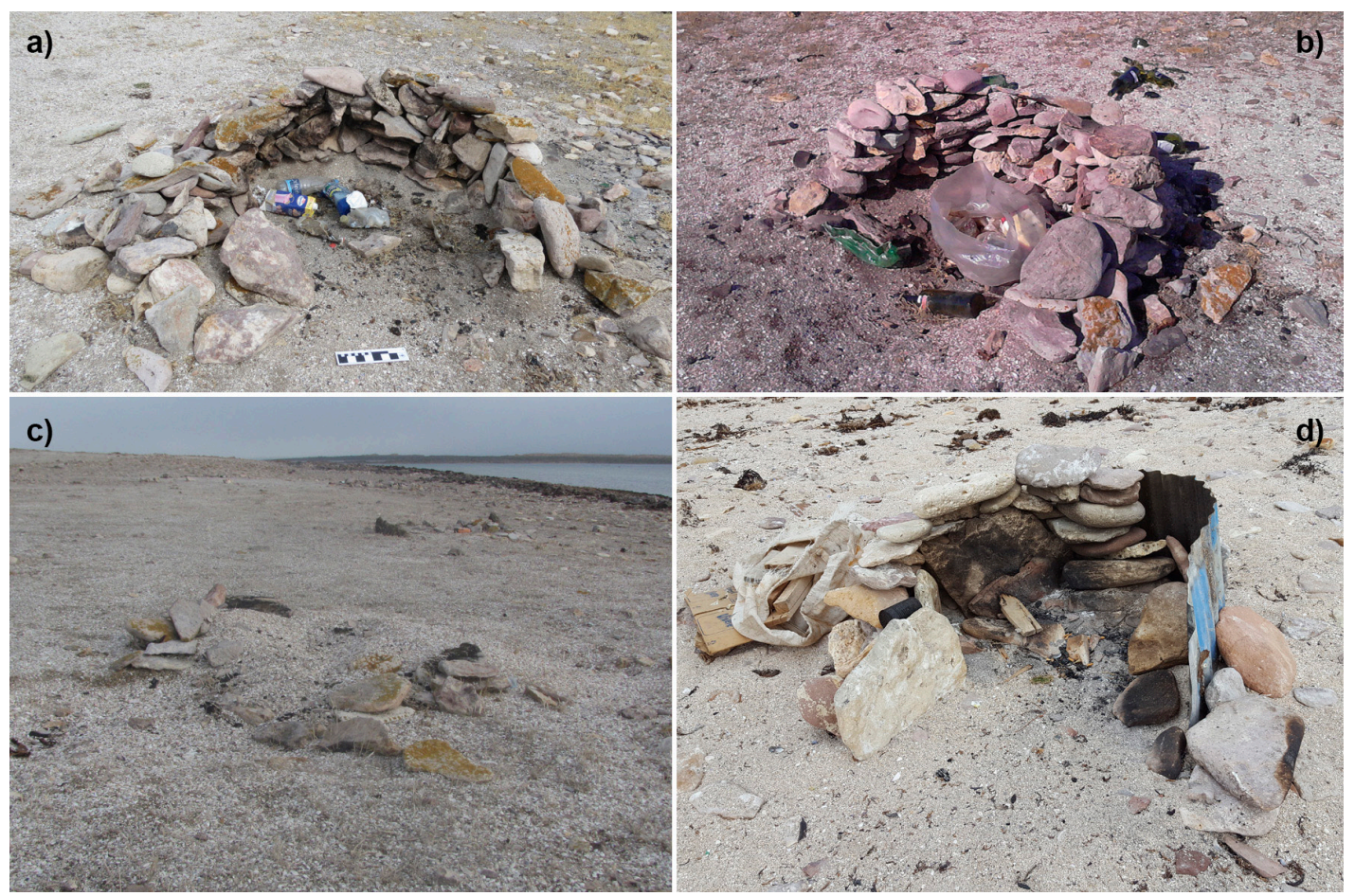

Fig. 11. Ejemplos de los pircados y fogones relevados en isla Liebres. Referencias: a) fogón construido solo con bloques rocosos, se observa en el espacio interior distintos tipos de basura (estructura I); b) fogón alto, cuenta con gran cantidad de basura en el espacio interior (estructura F); c) estructura indeterminada, que probablemente corresponde a un fogón desarmado y cubierto con el sedimento de isla Liebres (estructura G);

y d) fogón construido con bloques y chapas (estructura R).

en otras partes: la playa centro-este y la playa sur (Zubimendi, 2019b). Todos se ubican a menos de $40 \mathrm{~m}$ de la línea de playa, la cual habría sido la fuente probable de las rocas (Fig. 4). En la gran mayoría de los bloques de estas estructuras no se registraron líquenes en sus superficies (e. g. Fig. 11.a, b y d), con excepción de aquellos casos en los que probablemente se han reutilizado bloques extraídos de chenques (e. g. Fig. 7), donde se observan líquenes en caras no expuestas de las rocas, lo que refuerza que se trata de bloques movidos recientemente (Garibotti et al. 2011).

Las estructuras que denominamos pircados corresponden a alineamientos de piedras que apenas sobresalen de la superficie. Estos son de distinto tamaño, en general miden poco más de un metro de longitud y un ancho de aproximadamente $50 \mathrm{~cm}$ (Tabla 2). En el año 2001 se relevó un único pircado, los restantes fueron identificados en los distintos trabajos de campo. Se ubican en diferentes partes de la isla, por ejemplo, en el extremo sur fueron detectados dos alineamientos de bloques rocosos. La estructura $\mathrm{Q}$, registrada en el año 2001, tiene una extensión de $20 \mathrm{~m}$ y forma semicircular abierta, siendo la de mayores dimensiones de toda la isla. Presenta en las cercanías huesos de gran tamaño de cetáceos, así como dentro de la estructura, redes que se emplean en la captura de algas para su explotación comercial. En este caso, la estructura se habría creado de forma no intencional para sujetar la red, al apoyar los bloques sobre la misma. De acuerdo con referencias de los dueños de la estancia y la presencia de redes, se relacionarían con la explotación de algas de cachiyuyo (Macrocystis pyrifera), actividad económica que realizaron los dueños de la estancia durante las décadas de 1990 y parte del 2000 .

Otro caso a destacar es la estructura $\mathrm{K}$, que se ubica cerca de la concentración de chenques abiertos de la playa noroeste de la isla. Es probable que se haya generado a partir de la extracción de piedras que conformaban un chenque cercano, ya que se trata de una pequeña alineación de bloques 

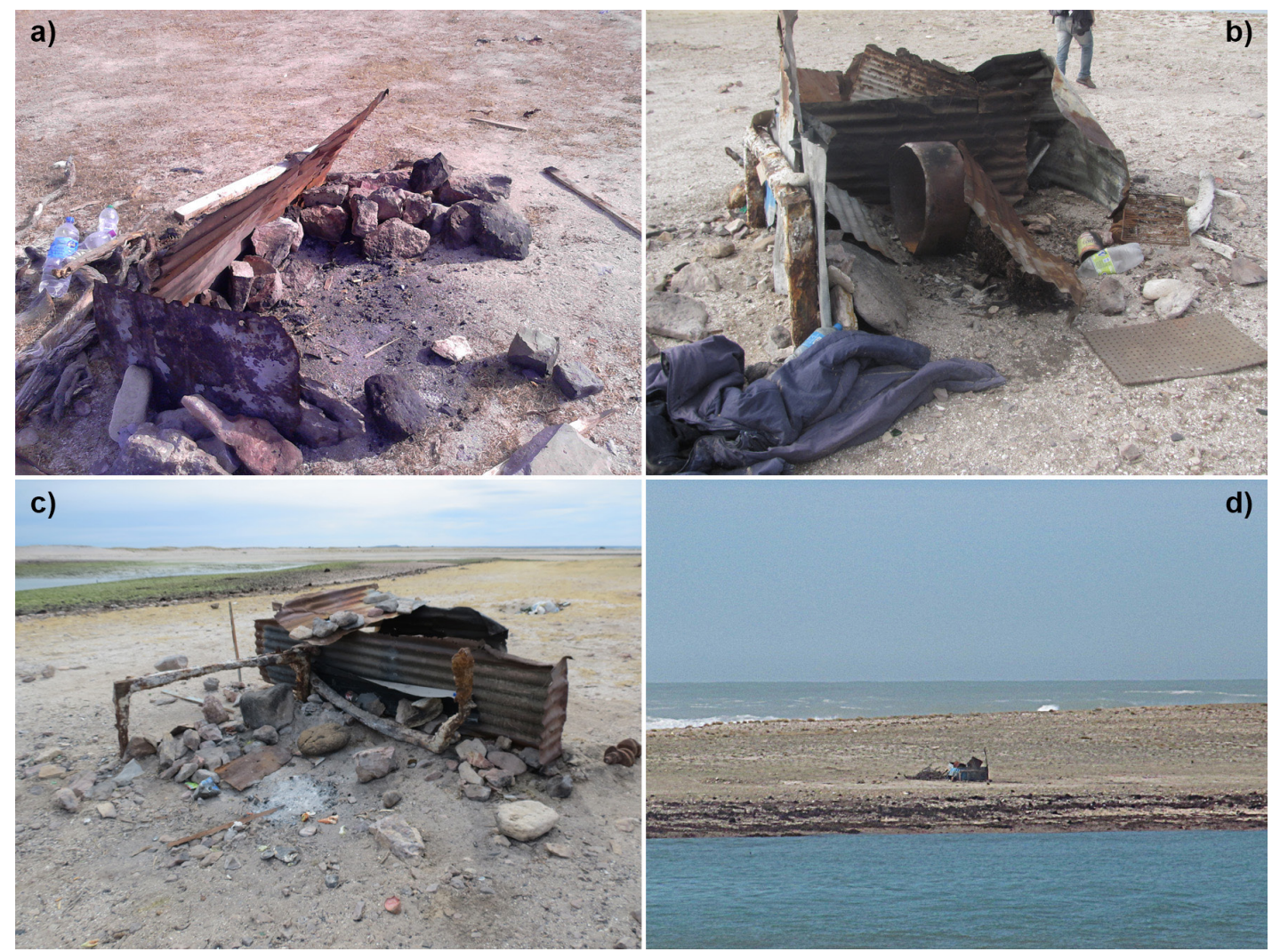

Fig. 12. Cambios en la estructura E. Referencias: a) relevamiento del año 2016; b) en el año 2017 se observa una mayor complejidad del mismo; c) en 2018 es más grande, se comprueba el uso de varias cuadernas metálicas provenientes de un naufragio (se puede ver una de ellas en la imagen del año anterior); y d) vista de la estructura desde la costa cercana.

grandes con un largo máximo de poco más de $1 \mathrm{~m}$ y un ancho menor a $50 \mathrm{~cm}$ (Fig. 13.a) identificada por primera vez en el año 2016 y modificada luego en el 2018. Los bloques parecieran haber sido removidos, ya que se encuentran parcialmente amontonados entre sí y la mayoría de las caras de los bloques expuestas no presenta líquenes, mientras que se observan superficies no expuestas con líquenes o apoyando sobre otras rocas. Esto podría estar indicando que sea el producto del acarreo y depositación reciente (Garibotti et al. 2011), probablemente provenientes de la deconstrucción de un chenque cercano, aunque no es posible estimar de cuál. En el año 2018 se comprobó que varios de estos bloques volvieron a ser retirados, y en el mismo lugar se realizó un fogón, quedando restos de carbón (Fig. 13.b).

En cuanto a las estructuras indeterminadas, dado que las mismas carecen de un ordenamiento claro de los bloques rocosos, es difícil interpretarlas. Éstas parecen corresponder a fogones derrumbados, desarmados o camadas de carbones tapados con sedimento ya que, en algunos casos, durante relevamientos previos en las mismas posiciones se habían registrado fogones.

También existe una importante y diversa contaminación con basura moderna dentro y en los alrededores de las estructuras recientes. De forma suelta en torno a éstas se observaron: metales, latas de conservas, latas de cerveza, botellas enteras o fragmentos de bebidas alcohólicas (cerveza, vino, bebidas blancas, por ejemplo), botellas de plástico de gaseosas y aceite, cartones de vino, cajas de cigarrillos, pilas, tanza de pescador, mamelucos, restos de pecios, e incluso juguetes infantiles. Mientras que a partir del 2017 se constató la confección de varios pozos de basura, en los que se descartaron principalmente botellas de bebidas 


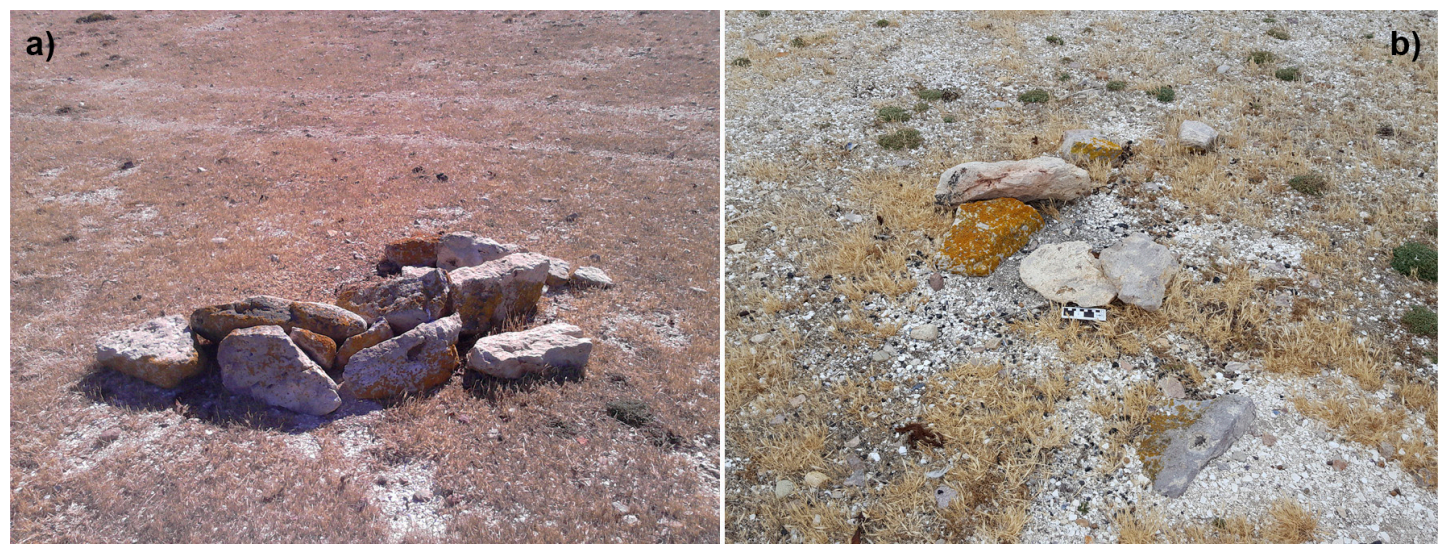

Fig. 13. Cambios en la estructura de piedra K. Referencias:

a) imagen del relevamiento del año 2016; y b) en el año 2018.

alcohólicas (Zubimendi, 2019b). Alrededor de las estructuras se registraron bolsas de plástico enganchadas en la vegetación herbácea. En algunas estructuras se observó también la presencia de tablas de madera y troncos de especies arbustivas que parecen haber sido acumulados y dejados para su uso como leña (Fig. 11.d). Cerca de otras estructuras se registraron varias extremidades de guanaco, animal que no habita en la isla Liebres. Todos estos elementos debieron haber sido traídos, incluso, el abandono de madera y leña podría implicar el equipamiento de este lugar y la planificación de retornar por parte de los que han hecho los pircados.

\section{DISCUSIÓN}

Los relevamientos realizados, separados entre sí por 17 años, nos permiten conocer no solo las características del registro arqueológico de la isla Liebres, sino también observar cambios que reflejan el accionar reciente del uso de este espacio con fines recreativos sin control. En este sentido, hasta el año 2013 la isla Liebres fue un espacio de acceso restringido, controlado por los dueños de la estancia. De acuerdo a referencias de los mismos y de pobladores de Puerto Deseado, a partir de dicho año la municipalidad de esta ciudad abrió el camino que conduce a la isla -de forma inconsulta con los dueños de la estancia, los investigadores que trabajan en la zona y el personal municipal encargado del área de Patrimonio-, lo que posibilitó acceder a la misma en todo momento. Esto, como queda claramente reflejado en este trabajo, genera una creciente degradación de la isla, no solo en relación al registro arqueológico, sino también al medio ambiente y el patrimonio natural, aunque estos últimos aspectos no son específicos de nuestra especialidad.

En general, las estructuras de piedra identificadas han sido clasificadas en dos categorías: de origen indígena -entierros de tipo chenque- y recientes. Si bien existen algunos antecedentes en la Patagonia para otros tipos de estructuras de piedra, como las acumulaciones o alineaciones de piedras (Martinic, 2002), pilas de piedras (Borrero et al. 2011; Borella et al. 2015), mojones (Magnin, 2013), incluso parapetos (Flores Coni, 2014), las estructuras identificadas en isla Liebres se diferencian claramente de todas éstas. En cuanto a estructuras de origen indígena, en su gran mayoría, las hemos considerado como chenques (Castro \& Moreno, 2000; Castro et al. 2001b; Zilio \& Zubimendi, 2014; Zilio, 2015, entre otros), cuya asignación se sustenta en la similitud morfo-estructural con otras definidas como tales en Patagonia (e.g. Goñi \& Barrientos, 2000; Reyes, 2002; Reyes et al. 2006; Magnin, 2013; Zilio, 2015). Estas estructuras podrían, a lo sumo, corresponder a aquellas que fueron identificadas como pseudochenques en la zona del río Cisnes (Aisén), esto es, acumulaciones de piedras "vacías", de dimensiones y características morfológicas similares a los chenques, pero en los que no se registran materiales arqueológicos (óseos, líticos, etc.). Han sido interpretados como marcadores territoriales, tumbas prepreparadas, hitos o falsos chenques para evitar el saqueo indiscriminado 
de las tumbas por parte de colonos (Goñi \& Barrientos, 2000; Goñi et al. 2004; Reyes et al. 2006). En el caso de isla Liebres, sin embargo, creemos que podrían tratarse de entierros de tipo chenque alterados, como los registrados en grandes cantidades en la CNSC (Castro \& Moreno, 2000; Castro et al. 2001a, 2001b; Zilio et al. 2013; Zilio \& Zubimendi, 2014; Zilio, 2015).

Los chenques de isla Liebres comparten características morfológicas con este tipo de enterratorios en el resto de la Patagonia y en particular de la CNSC. Si bien no se cuenta con cronología para los chenques identificados en isla Liebres, es plausible asumir que tienen una antigüedad de entre 1.000 y 300 años AP, que es el rango de este tipo de estructuras de entierro registrado en nuestra área de estudio (Zilio, 2015; Zubimendi et al. 2015a). Refuerza esta interpretación que la totalidad de la isla se ubica por debajo de los $10 \mathrm{msnm}$, altura máxima estimada para la ingresión marina del Holoceno medio (entre otros, Schellmann \& Radtke, 2010; Ponce et al. 2011) y que habría sido un espacio disponible y potencialmente utilizable solo en los últimos mil años (Zubimendi, 2019a).

Otro aspecto a considerar en relación a los chenques es la visibilidad y obstrusividad de las estructuras (sensu Magnin, 2013), ya que la gran mayoría se encuentra muy cerca del mar y sobre playas con pendientes moderadas, con un campo visual restringido orientado hacia el sureste, hacia la zona de la baliza de Punta Medanosa. Solo seis chenques se ubican en las cotas altas, en posiciones más alejadas de la costa y con una visibilidad a toda la isla, así como también a Punta Medanosa. Por otro lado, la totalidad de las estructuras fue confeccionada con rocas ignimbríticas inmediatamente disponibles en las playas cercanas. La gran mayoría estaría abierta o habría sido saqueada en algún momento en el pasado. Sus dimensiones promedio son mayores que aquellas definidas como cerradas; además presentan generalmente bloques de rocas distribuidos de forma anular o de anillo, con depresión central, la cual se ha inferido indicaría la apertura de la misma (Castro \& Moreno, 2000; Zilio \& Zubimendi, 2014; Zilio, 2015;).

Los análisis espaciales nos permiten observar que la localización de los chenques no es homogénea dentro de la isla, con una clara estructuración espacial de 27 chenques en la playa noroeste -y dentro de ésta, 19 en un sector acotado de solo $100 \times 30 \mathrm{~m}-$, mientras que el resto del perímetro litoral carece prácticamente de estructuras o se encuentran relativamente aisladas. Este tipo de agrupamientos de chenques ya ha sido identificado en otras partes de la CNSC, como Campo de Chenques al suroeste de Punta Medanosa (Castro \& Moreno, 2000; Zilio, 2015), Baliza y Ensenada Ferrer al norte de Punta Medanosa (Zubimendi, 2019a), y Playa Castillo y Playa de la Piedra en el sector de Bahía del Oso Marino (Zilio \& Zubimendi, 2014). Estas concentraciones de chenques han sido definidas como lugares persistentes (sensu Littleton \& Allen, 2007), ya que habrían sido reconocidos como posibles lugares de enterramiento donde afloran las rocas ignimbríticas aptas para su construcción. Luego, una vez hechos, podrían haber estructurado las actividades futuras, favoreciendo que dichos espacios sean utilizados y reutilizados para el entierro y no para otros fines. Por último, constituyen en sí mismos eventos de ocupación efectuados en momentos específicos que condicionaron el empleo dado a un sector determinado del paisaje (Littleton \& Allen, 2007; Prates \& Di Prado, 2013; Zilio, 2015). En este sentido, se destaca que donde existen estas concentraciones de entierros no se registran concheros, comprobándose una diferenciación espacial de espacios para fines inhumatorios y residenciales, proceso que ha sido identificado para el Holoceno tardío final en toda la localidad arqueológica Punta Medanosa (Zubimendi, 2019a).

Como hemos visto, las alteraciones identificadas en isla Liebres son diversas y complejas, pudiendo comprobarse la existencia de gran cantidad de estructuras no registradas en el primer relevamiento del año 2001. En su mayoría se trata de fogones o pircados, realizados probablemente por los visitantes de la isla para proteger el fuego del viento. Las nuevas estructuras se ubican mayormente muy cerca -menos de $300 \mathrm{~m}$ - del puente que conecta la isla Liebres con el continente, fácilmente accesible a pie o con vehículos. La cantidad de estructuras disminuye con la distancia del puente, así como también aumentó año a año en cada relevamiento. La estructura de piedra indígena 3 constituye un caso particular, dado que se trata de un chenque 
alterado para construir un fogón, lo que podría constituir un caso de reciclado del mismo para otros fines, algo que no se había registrado hasta la fecha en toda la CNSC.

En los relevamientos también se destaca la contaminación moderna, que consiste principalmente en basura vinculada con actividades de esparcimiento: desechos de comida y bebida, y que en su mayoría se asocia espacialmente a los fogones. La basura consta de una importante variabilidad, pero se destacan los restos de latas y botellas de vidrio y plástico de bebidas (vino, cerveza y gaseosas), entre otros. También se observa en menor medida basura vinculada a la pesca -como tanzas y cañas de pescar rotas- y otras que denotan la presencia de grupos familiares. La basura se encuentra principalmente en la franja de tierra al noroeste y en los primeros $300 \mathrm{~m}$ de la isla a partir del puente, a mayor distancia la basura en su mayoría consiste en botellas de vidrio o bolsas de plástico, estas últimas transportadas por el viento. Lamentablemente, la contaminación de contextos arqueológicos costeros no es exclusiva de la isla Liebres. Esta ha sido descrita, por ejemplo, por Manzi y Borella (2009) para la costa del golfo San Matías, y fue analizada en forma general en un trabajo previo para nuestra área de estudio (Zubimendi et al. 2015-2016). Sin embargo, pareciera que la velocidad y extensión de este proceso es mayor en esta isla, tal vez producto de la circunscripción espacial al tratarse de un espacio restringido, a diferencia de otros casos en la costa continental, que son más amplios.

A partir de los resultados de los relevamientos, es posible plantear una estructuración espacial para isla Liebres y definir cinco zonas de acuerdo con las características del registro arqueológico, las alteraciones que sufre y su estado de preservación actual (Fig. 14). Estos sectores reflejan en parte el uso prehistórico probable que le dieron a la isla Liebres las poblaciones del pasado, mientras que dan cuenta también del uso actual que se le está dando. La integración de estos resultados puede ser utilizada para definir políticas de mitigación y conservación de forma integral para proteger el patrimonio arqueológico y natural de esta particular isla.

1. Puente: este es el sector más cercano a la lengua de tierra que conecta la isla con el continente durante las mareas bajas. Si bien es de pequeñas dimensiones, es el que presenta mayores alteraciones recientes. Se encuentra altamente impactado por la construcción de pircados y la contaminación por parte de basura, ambas vinculadas con actividades de esparcimiento sin control. La basura está compuesta principalmente por materiales no biodegradables, por lo que si no se retiran se integrarán a los sedimentos $y$ al ambiente. Es probable que en el futuro continúe su degradación a un ritmo fuerte.

2. Playa noroeste: se ubica a continuación del anterior siguiendo la costa oeste de la isla. Es el sector que concentra la mayor densidad de evidencias arqueológicas, entre las que se destaca una agrupación de 27 chenques probablemente abiertos en la playa ubicada al noroeste. En este se observan menores alteraciones, principalmente basura, aunque en una densidad menor a la registrada en el sector anterior. Además, es donde se han registrado algunos chenques con basura y alteraciones con distintos grados de afectación. En el futuro, siguiendo las tendencias observadas en los últimos relevamientos, es probable que las alteraciones aumenten, afectando cada vez más al registro arqueológico.

3. Zona central: es el sector más extenso, con una baja densidad arqueológica, compuesta exclusivamente por chenques dispersos y aislados. No se registran alteraciones o contaminación en los chenques existentes y algunos de ellos han sido descritos como cerrados, lo que estaría denotando que esta parte de la isla Liebres ha sufrido menos alteraciones en el pasado. Sin embargo, por su ubicación, es probable que aumente la contaminación en este sector, principalmente de basura traída por el viento desde los sectores anteriores.

4. Playa centro-este: en esta zona se observaron por primera vez estructuras recientes en el relevamiento del año 2017, y al año siguiente se comprobaron nuevas estructuras. La contaminación se limita a los alrededores de los fogones y pircados. En distintas partes del intermareal cercano 


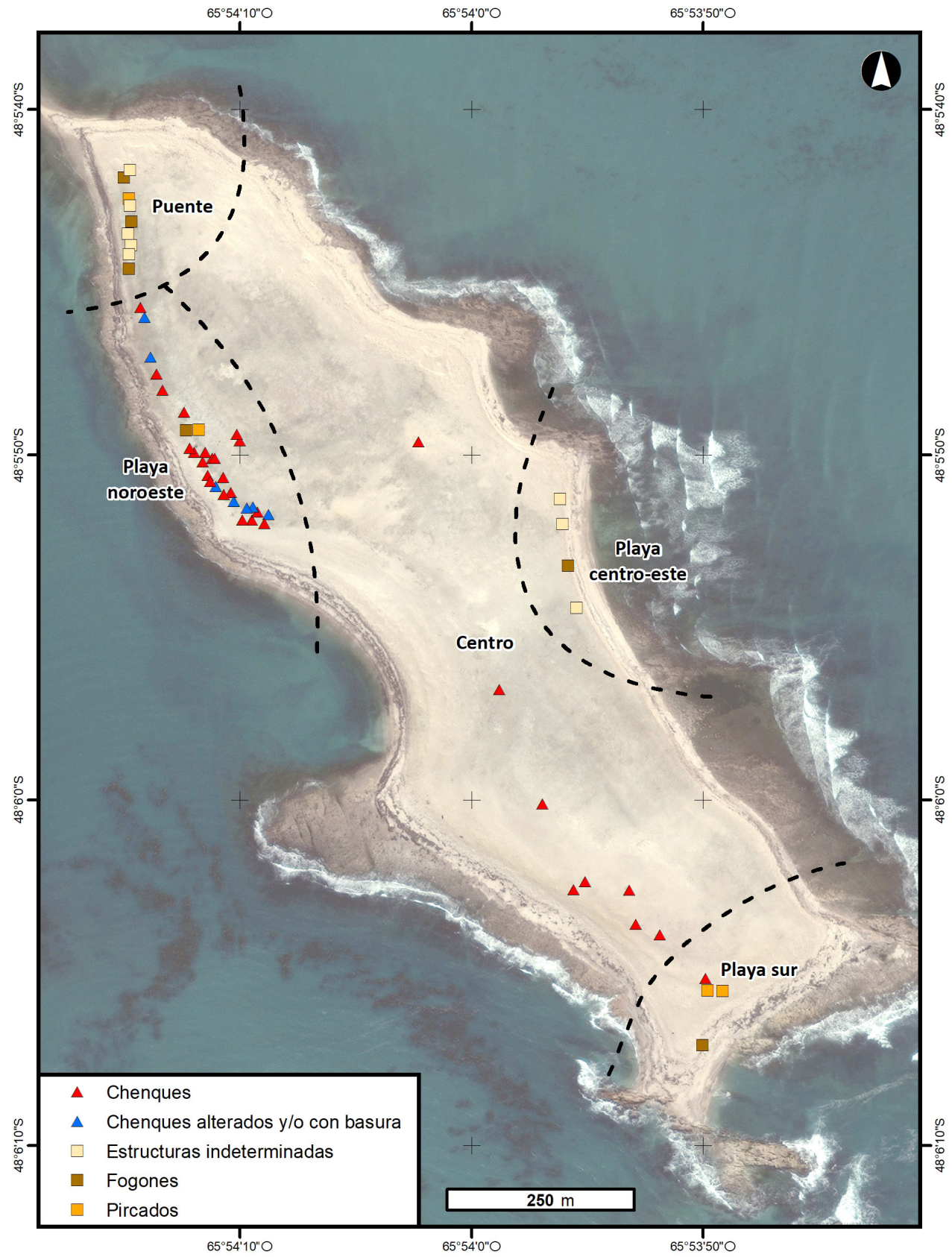

Fig. 14. Zonas en las que se divide isla Liebres a partir de las características del registro arqueológico, las alteraciones que sufre y su estado de preservación actual.

se observan distintas partes de un pecio, accesibles durante las mareas bajas.

5. Playa sur: es el sector más alejado del puente de tierra que comunica con el continente, de pequeñas dimensiones, en el cual se ha registrado un chenque no alterado, así como un pircado de dimensiones medianas a grandes, este último asociado a basura. Las alteraciones en estos últimos tienden a parecer limitadas, aunque podrían aumentar con un ritmo menor y espacialmente más limitadas que en los primeros sectores. 
Esta sectorización de la isla Liebres permite comprobar un avanzado proceso de alteración en el extremo norte de la isla, y en menor medida siguiendo la costa hasta la playa noroeste. Como hemos visto, las alteraciones incluyen la construcción de pircados y la contaminación con abundante basura, la cual no solo es probable que termine contaminando los sitios arqueológicos, sino que constituye una importante degradación del medio ambiente de la isla, donde anida gran cantidad de especies de aves. Por otro lado, es interesante resaltar que el riesgo al que se encuentra sometido el patrimonio arqueológico de isla Liebres no se vincula con el coleccionismo o el saqueo, que son las prácticas más comunes en la CNSC y, probablemente, en la provincia de Santa Cruz (Miotti \& Podgorny, 1997; Zubimendi et al. 2015-2016). La gran cantidad de basura y la alteración de las estructuras de piedra de tipo chenque, con acciones que incluyen la destrucción, modificación o reciclado de las mismas o de los bloques rocosos que las conforman, constituyen los mayores peligros. En este sentido, es importante señalar que esto implica la pérdida irreparable de los contextos de depositación y construcción de estos entierros, ya sea para realizar pircados para fogones o con otros fines que desconocemos.

Por otro lado, la coexistencia o contigüidad espacial de las estructuras de piedra indígenas y las recientes en una parte de isla Liebres puede generar en el futuro la dificultad de diferenciar, por ejemplo, entierros prehistóricos de estructuras modernas, dado que ambas podrían compartir características morfológicas una vez que los pircados se derrumbasen o la imposibilidad de detectar la presencia previa de chenques. Se han identificado distintos estadios de derrumbe de los pircados, a pesar de que éstos no presentan una alta antigüedad, y cambios entre los diferentes años. Probablemente haya que desarrollar criterios morfo-estructurales que permiten establecer las diferencias entre los chenques y los pircados, como el tamaño de los bloques, localización, emplazamiento, presencia de líquenes o marcas de combustión, entre otros. A su vez, hemos comprobado que se han utilizado

7 Por ejemplo, en el caso de la estructura 3, inicialmente no notamos que se trataba de un chenque, solo al comparar la ubicación geográfica con lo registrado en el año 2001 pudimos darnos cuenta que se trataba de un chenque que bloques ignimbríticos de entierros para ser usados en la confección de los pircados de fogones o indeterminados, lo que implica una modificación de la estructura y podría dificultar aún más la identificación de los chenques ${ }^{7}$.

Todos estos elementos son de importancia, dado que la práctica de esparcimiento en la costa patagónica es muy común, lo que, junto con el aumento poblacional y el auge del turismo cercano a la naturaleza, permiten plantear que situaciones de este tipo en las que el registro arqueológico se ve afectado -ya sea mediante la contaminación con basura o las modificaciones de estructurasaumentarán a futuro.

\section{PALABRAS FINALES}

Los trabajos realizados en isla Liebres no solo han permitido conocer las características del registro arqueológico superficial de la isla, sino que, dado que los relevamientos fueron hechos con 17 años de diferencia, brindan la posibilidad de generar un análisis longitudinal y observar los cambios que han ocurrido en algunas de las estructuras identificadas.

En cuanto al uso prehistórico de isla Liebres, los resultados de los relevamientos realizados permiten plantear que parte de la misma -concretamente la playa noroeste- fue un espacio utilizado de forma recurrente para la realización de prácticas mortuorias (Littleton \& Allen, 2007). Este espacio fue seleccionado para tal fin a pesar de que a priori presenta características geomorfológicas similares al resto del perímetro costero de la isla. Eso constituye sin duda un contexto interesante y excepcional en la costa patagónica, ya que no solo es un caso más de agrupamiento de chenques costeros -como Campo de Chenques, Baliza, Ensenada Ferrer, Playa de la Piedra y Playa Castillo (Zilio \& Zubimendi, 2014; Zilio, 2015)- sino que además se suma la particularidad de tratarse de una isla que se conecta con el continente solo unas horas al día. Sin duda, este agrupamiento de chenques contribuye a la discusión de la presencia de áreas formales de entierro en la CNSC (Zilio,

había sido registrado previamente y que se encontraba alterado, lo que luego fue corroborado mirando en las fotografías otras variables, como la presencia y disposición de los líquenes. 
2015), así como en relación con los procesos de cambios, intensificación en el uso de la costa patagónica y la reducción de la movilidad en nuestra área de estudio durante el Holoceno tardío final (Hammond, 2015; Zubimendi, 2010, 2019a; Moreno, 2009; Ambrústolo, 2011; Hammond, 2015; Zilio, 2015).

Mientras que en relación al uso actual de isla Liebres, se destaca que se encuentra sometida a una fuerte presión por parte de los visitantes ocasionales que realizan actividades de esparcimiento sin ningún tipo de control y con prácticas agresivas sobre el registro arqueológico y el patrimonio natural. Esta presión se ve reflejada en la generación de nuevas estructuras de piedra, la alteración de aquellas ya existentes, y una importante contaminación por basura. En este sentido, lo ocurrido en isla Liebres desde que el acceso a la misma es irrestricto, puede ser visto como el producto y el resultado de la falta de planificación en la gestión del patrimonio arqueológico por parte de las autoridades que provocaron la misma, dado que con la gran cantidad de antecedentes que existía sobre el valor del registro arqueológico de Punta Medanosa habría requerido un análisis previo y la consulta con especialistas o agentes locales vinculados con el patrimonio. Todo esto colabora con la degradación de un paisaje natural y cultural que debería ser protegido y cuidado, y que podría incorporarse a circuitos turísticos que permitieran la generación de nuevas fuentes de recursos económicos en una zona en permanente crisis por la baja rentabilidad de la lana, el abandono del mundo rural y la falta de políticas que acompañen a los estancieros $y$ productores ganaderos.

\section{AGRADECIMIENTOS}

Quisiera agradecer especialmente a la familia Vidal, Luli y Sergio, por la logística de campo y facilitarnos todos los trabajos en su estancia. También a quienes han participado en distintos momentos de los trabajos de campo en isla Liebres: Catalina Peña, Rocío Giménez, María Andolfo, Eduardo Moreno, Pablo Ambrústolo, Joaquín Rumbo, Carolina Contreras, así como especialmente a Soledad Caracotche y Rocío Blanco. Estos trabajos se realizaron en el marco de los proyectos "Estudios regionales en el eje
Deseado para definir los rangos de acción de grupos cazadores recolectores costeros en el marco de la ocupación humana del Holoceno de Patagonia (N739)" y PICT 2014-3591 "Localidad arqueológica Punta Medanosa: cambios geomorfológicos y arqueológicos a lo largo del Holoceno medio y tardío" del cual soy director.

\section{BIBLIOGRAFÍA}

Ambrústolo, P. (2011). Estudio de las estrategias de aprovisionamiento y utilización de los recursos líticos por grupos cazadores-recolectores en la Costa Norte de Santa Cruz (Patagonia - Argentina). Tesis doctoral. Facultad de Ciencias Naturales y Museo, Universidad Nacional de La Plata, La Plata.

Beron, M., Baffi, E. I., Molinari, R., Barrientos, G., Aranda, C., \& Luna, L. (2000). Estructuras funerarias de momentos tardíos en Pampa-Patagonia. El Chenque de Lihué Calel. En E. Espinosa (Ed.), Desde el país de los Gigantes. Perspectivas arqueológicas en Patagonia (pp. 141-160). Río Gallegos: Universidad Nacional de la Patagonia Austral.

Borella, F., Cardillo, M., Favier Dubois, C., \& Alberti, J. (2015). Nuevas investigaciones arqueológicas entre punta Pórfido y punta Odriozola: implicancias para el entendimiento de la dinámica de las ocupaciones humanas en la costa oeste del golfo San Matías (Río Negro). Relaciones de la Sociedad Argentina de Antropología, XL(1), 233-252.

Borrero, L. A. (1988). Tafonomía Regional. En N. Ratto y A. Haber (Eds.). De Procesos, Contextos y Otros Huesos (pp. 9-15). Buenos Aires: ICA, Sección Prehistoria, Facultad de Filosofía y Letras, Universidad de Buenos Aires.

Borrero, L. A., Borrazo, K., Garibotti, I., \& Pallo, C. (2011). Concentraciones de pilas de rocas en la cuenca superior del río Santa Cruz (Argentina). Magallania, 39(2), 193206.

Carrara, I. S. (1952). Lobos marinos, pingüinos y guaneras de las costas del litoral marítimo e islas adyacentes de la República Argentina. La Plata: Facultad de Ciencias Veterinarias, Universidad Nacional de La Plata. Publicación especial de la Cátedra de Higiene e Industrias.

Castro, A., \& Moreno, E. (2000). Noticia sobre enterratorios humanos en la costa Norte de Santa Cruz - Patagonia Argentina. Anales del Instituto de la Patagonia, Serie Ciencias Humanas, 28, 225-232. 
Castro, A., Zubimendi, M. A. \& Peña, C. (2000). Proyecto arqueológico de rescate en el Cañadón del Duraznillo (Reserva Natural Fundación Vida Silvestre). Informe técnico, Fundación Vida Silvestre.

Castro, A., Moreno, E., Andolfo, M. A., \& Zubimendi, M. Á. (2001a). Distribución espacial de sitios en la localidad de Punta Medanosa. Relaciones de la Sociedad Argentina de Antropología, XXVI, 303-322.

Castro, A., Moreno, E. \& Peña, C. (2001b). Los entierros de la localidad Punta Medanosa y Campo de Chenques: distribución y variabilidad. Trabajo presentado en Puerto Natales en el Taller Internacional de Arqueología de Entierros Humanos en Fuego Patagonia.

Castro, A., Moreno, E., Zubimendi, M. Á., Andolfo, M. A., Giménez, R., \& Peña, C. (2001c). Uso funerario y habitacional en la localidad de Punta Medanosa. Santa Cruz (Argentina). En Libro de Resúmenes y Cronograma de Actividades del XIV Congreso Nacional de Arqueología Argentina (pp. 75-76). Rosario: Universidad Nacional del Rosario, Facultad de Humanidades y Arte.

Cevasco, C., Frere, E., \& Gandini, P. (2001). Intensidad de visitas como condicionante de la respuesta del pingüino de Magallanes (Spheniscus magellanicus) al disturbio humano. Ornitologia Neotropical, 12, 75-81.

Flores Coni, J. (2014). Análisis de la variabilidad de los parapetos en la meseta del Strobel (Santa Cruz). Relaciones de la Sociedad Argentina de Antropología, XXXIX(2), 551-557.

Garibotti, I., Borrazo, K., \& Borrero, L. A. (2011). Aplicación de técnicas liquenométricas en la arqueología de Patagonia utilizando Rhizocarpon subgénero Rhizocarpon. En L.A. Borrero y K. Borrazo (Eds.) Bosques, montañas y cazadores. Investigaciones arqueológicas en Patagonia meridional (pp. 85-104). Buenos Aires: Editorial Dunken.

Giacosa, R. E., Césari, O., \& Genini, A. (1998). Descripción de la Hoja Geológica 4766 - III y IV. Puerto Deseado, Provincia de Santa Cruz, Tomo 240 de Boletín del Programa Nacional de Cartas Geológicas de la República Argentina 1:250.000. Dirección Nacional del Servicio Geológico, Buenos Aires.

Goñi, R. A., \& Barrientos, G. (2000). Estudio de chenques en el lago Salitroso, Provincia de Santa Cruz. En E. Espinosa (Ed.), Desde el país de los Gigantes. Perspectivas arqueológicas en Patagonia (pp. 161-175). Río Gallegos: Universidad Nacional de la Patagonia Austral.

Goñi, R., Barrientos, G., Figuerero, M., Mengoni, G., Mena, F., Lucero, V., \& Reyes, O. (2004). Distribución espacial de entierros en la cordillera de Patagonia centromeridional
(Lago Salitroso-Paso Roballos, Argentina. Entrada Baker-Chacabuco, Chile). Chungará, 36(suplemento especial 2), 1101-1107.

Goñi, R. A., Barrientos, G., \& S. García Guráieb, S. (2005). Análisis preliminar del material óseo humano recuperado en el Chenque $N^{\circ} 1$, sitio Campo de Chenques, Punta Medanosa (Provincia de Santa Cruz). Informe técnico, Instituto Nacional de Antropología y Pensamiento Latinoamericano.

Grandi, M. F., Dans, S. L., \& Crespo, E. A. (2015). The recovery process of a population is not always the same: The case of Otaria flavescens. Marine Biology Research, 11(3), 225-235.

Hammond, H. (2015). Sitios Concheros en la Costa Norte de Santa Cruz: su estructura arqueológica y variabilidad espacial en cazadores recolectores patagónicos. Tesis doctoral. Facultad de Ciencias Naturales y Museo, Universidad Nacional de La Plata, La Plata.

Littleton, J., \& Allen, H. (2007). Hunter-gatherer burials and the creation of persistent places in southeastern Australia. Journal of Anthropological Archaeology, 26(2), 283-298.

Magnin, L. (2013). Análisis de visibilidad aplicado a estructuras rocosas en la localidad La Primavera, Santa Cruz. Arqueología, 19(2), 325-346.

Manzi, L., \& Borella, F. (2009). Disturbaciones antrópicas recreativas del registro arqueológico en la costa del golfo San Matías, Provincia de Río Negro, Argentina. En $53^{\circ}$ Congreso Internacional de Americanistas, México D. F., México.

Martinic, M. (2002). Estructuras de piedra en la Patagonia austral oriental. Anales del Instituto de la Patagonia, Serie Ciencias Humanas, 30, 103-115.

Miotti, L. L., \& Podgorny, I. (1997). Una flecha en mi sopa: la convivencia con los restos arqueológicos en la región del Deseado, Santa Cruz, Argentina. Cuadernos del Instituto Nacional de Antropología y Pensamiento Latinoamericano, 16, 343-356.

Moreno, J. E. (2009). Arqueología y etnohistoria de la Costa Patagónica Central en el Holoceno Tardío. Fondo Editorial Provincial. Secretaría de Cultura del Chubut.

Ponce, J. F., Rabassa, J., Coronato, A., \& Borromei, A. M. (2011). Palaeogeographical evolution of the Atlantic coast of Pampa and Patagonia from the last glacial maximum to the Middle Holocene. Biological Journal of the Linnean Society, 103, 363-379.

Prates, L., \& Di Prado, V. (2013). Sitios con entierros humanos y ocupaciones residenciales en la cuenca del río Negro (norpatagonia, argentina). Diacronía y multicausalidad. 
Latin American Antiquity, 24(4), 451-466.

Reyes, O. (2002). Funebria indígena en el curso inferior del valle del río Ibáñez, margen occidental de la estepa centropatagónica (XI Región de Aisén). Anales del Instituto de la Patagonia, Serie Ciencias Humanas, 30, 87-102.

Reyes, O., \& Méndez, C. (2010). Precisando la cronología para la inhumación tipo chenque, valle del río Cisnes (Aisén, Chile), Patagonia Central. Magallania, 38(2), 127-132.

Reyes, O., Méndez, C., Velázquez, H., \& Trejo, V. (2006). Distribuciones espaciales y contextos arqueológicos de cazadores recolectores esteparios en Alto río Cisnes (XI Región de Aisén). Magallania, 34(2),75-90.

Salceda, S., Méndez, M. G., Castro, A., \& Moreno, J. (19992001). Enterratorios indígenas de Patagonia: el caso del sitio Heupel - Caleta Olivia, Santa Cruz (Argentina). Xama, 12-14, 161-171.

Schellmann, G., \& Radtke, U. (2010). Timing and magnitude of Holocene sea-level changes along the middle and south Patagonian Atlantic coast derived from beach ridge systems, littoral terraces and valley-mouth terraces. Earth-Science Reviews, 103, 1-30.

Schiavini, A., Yorio, P., Gandini, P. A., Raja Rey, A., \& Dee Boerma, P. (2005). Los pingüinos de las costas argentinas: estado poblacional y conservación. Hornero, 20(1), 5-23.

Yorio, P. (2005). Estado poblacional y de conservación de gaviotines y escúas que se reproducen en el litoral marítimo argentino. Hornero, 20(1), 75-93.

Zilio, L. (2013). Chenques en Patagonia centro-meridional: análisis de los patrones de distribución espaciotemporales. Comechingonia, 17, 237-254.

Zilio, L. (2015). Prácticas mortuorias en la costa norte de Santa Cruz: arqueología de sociedades cazadoras recolectoras en paisajes costeros de la Patagonia argentina. Tesis doctoral. Facultad de Ciencias Naturales y Museo, Universidad Nacional de La Plata, La Plata.

Zilio, L., Zubimendi, M. Á., \& Hammond, H. (2013). Chenques en un paisaje costero: análisis de estructuras de entierro en Punta Medanosa. Anuario de Arqueología, 5, 253267.
Zilio, L., \& Zubimendi, M. Á. (2014). Estudio de la distribución de estructuras de entierro en poblaciones cazadoras recolectoras de la costa norte de Santa Cruz (Patagonia Argentina). Revista Española de Arqueología Americana, 44(1), 105-126.

Zubimendi, M. Á. (2010). Estrategias de uso del espacio por grupos cazadores recolectores en la Costa Norte de Santa Cruz y su interior inmediato. Tesis doctoral. Facultad de Ciencias Naturales y Museo, Universidad Nacional de La Plata, La Plata.

Zubimendi, M. Á. (2019a). Cambios y continuidades a lo largo del Holoceno en el uso humano de la localidad arqueológica Punta Medanosa (Patagonia argentina). Relaciones de la Sociedad Argentina de Antropología, XLIV(1), 107-129.

Zubimendi, M. Á. (2019b). Análisis de alteraciones antrópicas recientes y su impacto sobre el registro arqueológico en la isla Liebres (costa norte de Santa Cruz). En J. Gómez Otero, A. Svoboda \& A. Banegas (Comps.), Arqueología de Patagonia: el pasado en las arenas (pp. 455-467). Puerto Madryn: Instituto de Diversidad y Evolución Austral.

Zubimendi, M. Á., \& Ambrústolo, P. (2016). Estudio comparativo de abrigos rocosos en la costa norte de Santa Cruz (Patagonia). Comechingonia, 20(1), 253276.

Zubimendi, M. Á., Hammond, H., \& Zilio, L. (2015a). Síntesis regional de las malacofaunas arqueológicas de la costa patagónica continental argentina. En H. Hammond \& M. Á. Zubimendi (Eds.), Arqueomalacología: abordajes metodológicos y casos de estudio en el Cono Sur (pp. 175-215). Buenos Aires: Fundación de Historia Natural Félix de Azara.

Zubimendi, M. Á., Ambrústolo, P., Zilio, L., \& Castro, A. (2015b). Continuity and discontinuity in the human use of the north coast of Santa Cruz (Patagonia Argentina) through its radiocarbon record. Quaternary International, 356, 127-146.

Zubimendi, M. Á., Hammond, H., Zilio, L., Ambrústolo, P., \& Castro, A. (2015-2016). Análisis de los agentes de alteración del registro arqueológico identificados en la costa norte de Santa Cruz (Patagonia Argentina). Anales de Arqueología y Etnología, 70-71, 159-180. 
